\title{
Role of Artificial Intelligence in Patient Safety Outcomes: Systematic Literature Review
}

Avishek Choudhury, MSc; Onur Asan, PhD

School of Systems and Enterprises, Stevens Institute of Technology, Hoboken, NJ, United States

Corresponding Author:

Onur Asan, $\mathrm{PhD}$

School of Systems and Enterprises

Stevens Institute of Technology

1 Castle Point Terrace

Hoboken, NJ, 07030

United States

Phone: 12012168901 ext 2012168901

Email: oasan@stevens.edu

\section{Abstract}

Background: Artificial intelligence (AI) provides opportunities to identify the health risks of patients and thus influence patient safety outcomes.

Objective: The purpose of this systematic literature review was to identify and analyze quantitative studies utilizing or integrating AI to address and report clinical-level patient safety outcomes.

Methods: We restricted our search to the PubMed, PubMed Central, and Web of Science databases to retrieve research articles published in English between January 2009 and August 2019. We focused on quantitative studies that reported positive, negative, or intermediate changes in patient safety outcomes using AI apps, specifically those based on machine-learning algorithms and natural language processing. Quantitative studies reporting only AI performance but not its influence on patient safety outcomes were excluded from further review.

Results: We identified 53 eligible studies, which were summarized concerning their patient safety subcategories, the most frequently used AI, and reported performance metrics. Recognized safety subcategories were clinical alarms ( $\mathrm{n}=9$; mainly based on decision tree models), clinical reports ( $n=21$; based on support vector machine models), and drug safety ( $n=23$; mainly based on decision tree models). Analysis of these 53 studies also identified two essential findings: (1) the lack of a standardized benchmark and (2) heterogeneity in AI reporting.

Conclusions: This systematic review indicates that AI-enabled decision support systems, when implemented correctly, can aid in enhancing patient safety by improving error detection, patient stratification, and drug management. Future work is still needed for robust validation of these systems in prospective and real-world clinical environments to understand how well AI can predict safety outcomes in health care settings.

(JMIR Med Inform 2020;8(7):e18599) doi: 10.2196/18599

\section{KEYWORDS}

artificial intelligence; patient safety; drug safety; clinical error; report analysis; natural language processing; drug; review

\section{Introduction}

Patient safety is defined as the absence of preventable harm to a patient and minimization of the risk of harm associated with the health care process [1,2]. Every part of the care-giving process involves a certain degree of inherent risk. Since resolution WHA55.18 on "Quality of Care: Patient Safety" at the 55th World Health Assembly was proposed in 2002, there has been increasing attention paid to patient safety concerns and adverse events in health care settings [3]. Despite the safety initiatives and investments made by federal and local governments, private agencies, and concerned institutions, studies continue to report unfavorable patient safety outcomes $[4,5]$.

The integration of artificial intelligence (AI) into the health care system is not only changing dynamics such as the role of health care providers but is also creating new potential to improve patient safety outcomes [6] and the quality of care [7]. The term 
AI can be broadly defined as a computer program that is capable of making intelligent decisions [8]. The operational definition of AI we adopt in this review is the ability of a computer or health care device to analyze extensive health care data, reveal hidden knowledge, identify risks, and enhance communication [9]. In this regard, AI encompasses machine learning and natural language processing. Machine learning enables computers to utilize labeled (supervised learning) or unlabeled (unsupervised learning) data to identify latent information or make predictions about the data without explicit programming [9]. Among different types of AI, machine learning and natural language processing specifically have societal impacts in the health care domain [10] and are also frequently used in the health care field [9-12].
The third category within machine learning is known as reinforcement learning, in which an algorithm attempts to accomplish a task while learning from its successes and failures [9]. Machine learning also encompasses artificial neural networks or deep learning [13]. Natural language processing focuses on building a computer's ability to understand human language and consecutively transform text to machine-readable structured data, which can then be analyzed by machine-learning techniques [14]. In the literature, the boundary defining natural language processing and machine learning is not clearly defined. However, as illustrated in Figure 1, studies in the field of health care have been using natural language processing in conjunction with machine-learning algorithms [15].

Figure 1. Schematic illustration of how natural language processing converts unstructured text to machine-readable structured data, which can then be analyzed by machine-learning algorithms.

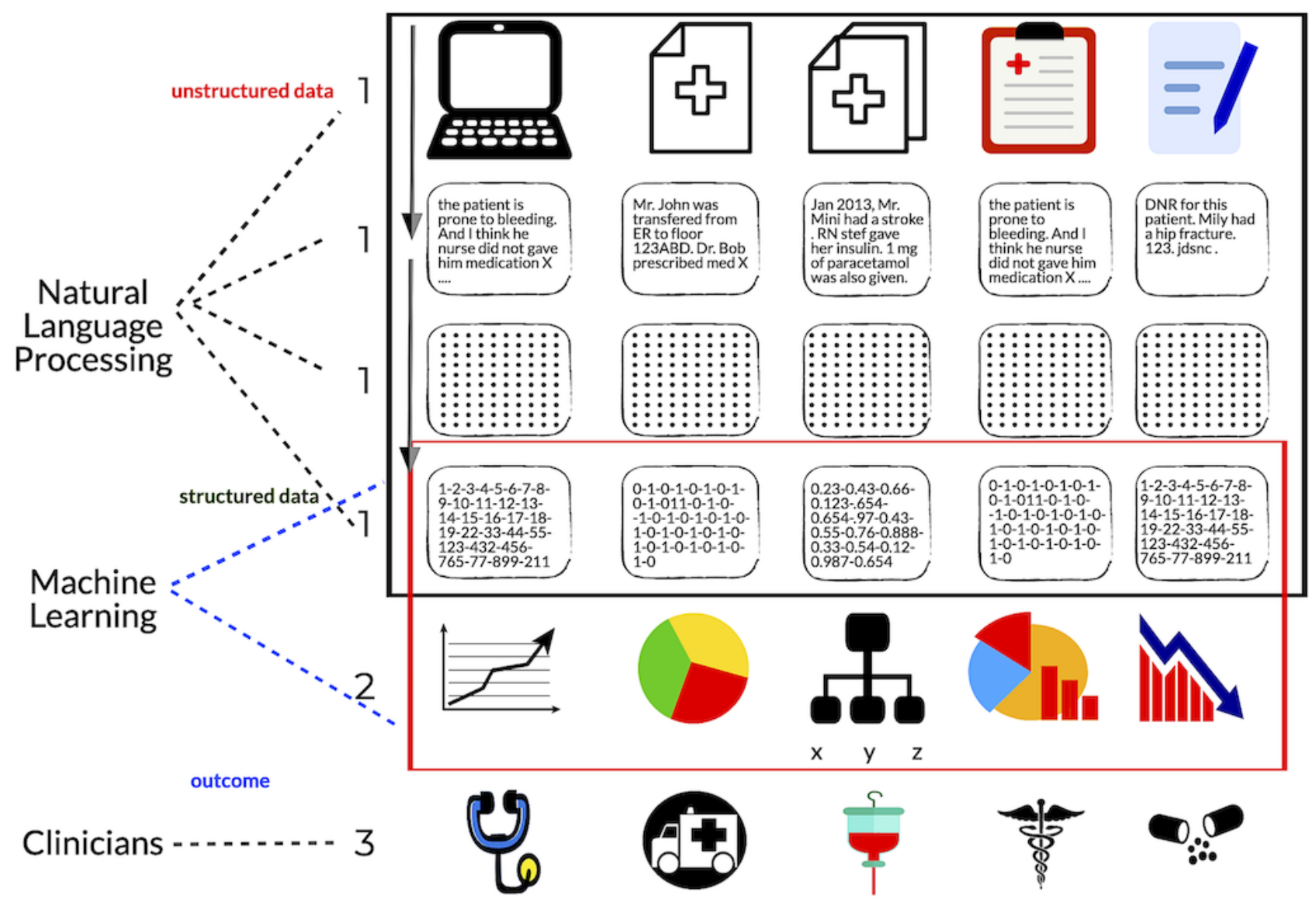

AI has potential to assist clinicians in making better diagnoses [16-18], and has contributed to the fields of drug development [19-21], personalized medicine, and patient care monitoring [14,22-24]. AI has also been embedded in electronic health record (EHR) systems to identify, assess, and mitigate threats to patient safety [25]. However, with the deployment of AI in health care, several risks and challenges can emerge at an individual level (eg, awareness, education, trust), macrolevel (eg, regulation and policies, risk of injuries due to AI errors), and technical level (eg, usability, performance, data privacy and security).
The measure of AI accuracy does not necessarily indicate clinical efficiency [26]. Another common measure, the area under the receiver operating characteristic curve (AUROC), is also not necessarily the best metric for clinical applicability [27]. Such AI metrics might not be easily understood by clinicians or might not be clinically meaningful [28]. Moreover, AI models have been evaluated using a variety of parameters and report different measure(s) such as the $F 1$ score, accuracy, and false-positive rate, which are indicative of different aspects of AI's analytical performance. Understanding the functioning of complex AI requires technical knowledge that is not common 
among clinicians. Moreover, clinicians do not necessarily have the training to identify underlying glitches of the AI, such as data bias, overfitting, or other software errors that might result in misleading outcomes. Such flaws in AI can result in incorrect medication dosage and poor treatment [29-33].

Furthermore, a system error in a widely used AI might lead to mass patient injuries compared to a limited number of patient injuries due to a provider's error [34]. Additionally, there have been instances where traditional analytical methods outperformed machine-learning techniques [9]. Owing to the wide range of effectiveness of AI, it is crucial to understand both the promising and deterring impacts of $\mathrm{AI}$ on patient safety outcomes [35].

AI in the health care system can assist at both the "clinical" and "diagnostic" levels [36]. AI provides a powerful tool that can be implemented within the health care domain to reveal subtle patterns in data, and these patterns can then be interpreted by clinicians to identify new clinical and health-related issues [9]. Recent studies and reviews have primarily focused on the performance of AI at the diagnostic level, such as for disease identification [37-42], and the application of AI robotics in surgery and disease management [43-46]. Other studies have also implemented AI technologies to assist at the clinical level, including assessing fall risks [47] and medication errors [48,49]. However, many of these studies are centered around AI development and performance and there is a notable lack of studies reviewing the role and impact of AI used at the clinical level on patient safety outcomes.

Many studies have reported high accuracy of AI in health care. However, its actual influence (negative or positive) can only be realized when it is integrated into clinical settings or interpreted and used by care providers [50]. Therefore, in our view, patient safety and AI performance might not necessarily complement each other. AI in health care depends on data sources such as EHR systems, sensor data, and patient-reported data. EHR systems may contain more severe cases for specific patient populations. Certain patient populations may have more ailments or may be seen at multiple institutions. Certain subgroups of patients with rare diseases may not exist in sufficient numbers for a predictive analytic algorithm. Thus, clinical data retrieved from EHRs might be prone to biases [9,50]. Owing to these potential biases, AI accuracy might be misleading [51] when trained on a small subgroup or small sample size of patients with rare ailments.

Furthermore, patients with limited access to health care may receive fewer diagnostic tests and medications and may have insufficient health information in the EHR to trigger an early intervention [52]. In addition, institutions record patient information differently; as a result, if AI models trained at one institution are implemented to analyze data at another institution, this may result in errors [52]. For instance, machine-learning algorithms developed at a university hospital to predict patient-reported outcome measures, which tend to be documented by patients who have high education as well as high income, may not be applicable when implemented at a community hospital that primarily serves underrepresented patient groups with low income.

A review [53] conducted in 2017 reported that only about 54\% of studies that developed prediction models based on EHRs accounted for missing data. Recent studies and reviews have been primarily focusing on the performance and influence of AI systems at a diagnostic level, such as for disease identification [37-42], and the influence of AI robotics in surgery and disease management [43-46]; however, there is a lack of studies reviewing and reporting the impact of AI used at the clinical level on patient safety outcomes, as well as characteristics of the AI algorithms used. Thus, it is essential to study how AI has been shown to influence patient safety outcomes at the clinical level, along with reported AI performance in the literature. In this systematic review, we address this gap by exploring the studies that utilized AI algorithms as defined in this review to address and report changes in patient safety outcomes at the clinical level (Figure 2).

Figure 2. Artificial intelligence (AI) route to patient safety via "Clinical" and "Diagnostic" level interventions. DSS: decision support system.

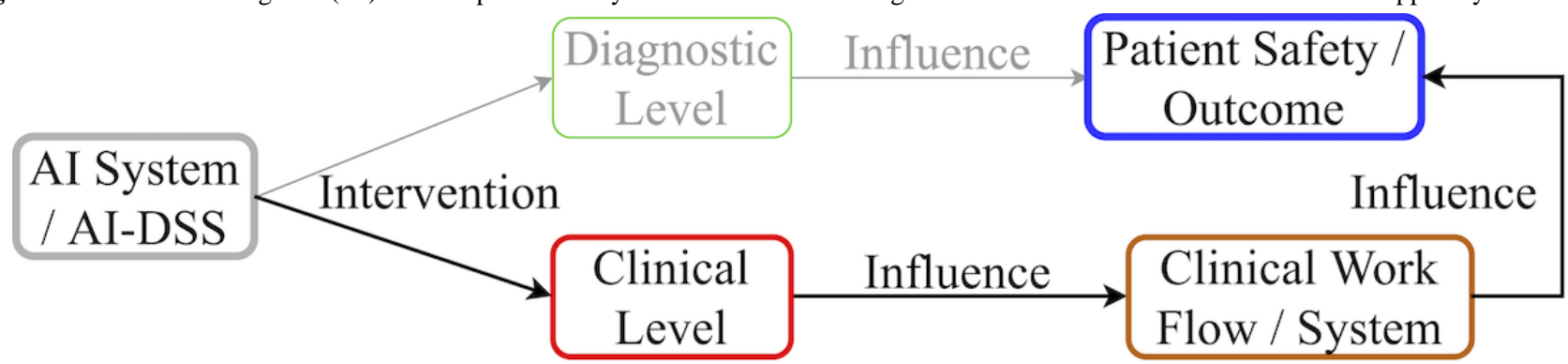

\section{Methods}

\section{Protocol Registration}

This systematic review is reported according to the Preferred Reporting Items for Systematic Reviews and Meta-Analysis (PRISMA) guidelines [54]. We followed the PRISMA Checklist (see Multimedia Appendix 1). Our protocol [55] was registered with the Open Science Framework on September 15, 2019.

\section{Information Sources}

We searched for peer-reviewed publications in the PubMed, PubMed Central, and Web of Science databases from January 2009 to August 2019 to identify articles within the scope and eligibility criteria of this systematic literature review.

\section{Search Strategy}

We followed a systematic approach of creating all search terms to capture all related and eligible papers in the searched 
databases. Keywords used in the search were initially determined by a preliminary review of the literature and then modified based on feedback from content experts as well as our institution's librarian.

We then refined the search strategy in collaboration with the librarian to ensure that all clinical-level patient safety-related papers (as shown in Figure 2) were covered in our review and determined the Medical Subject Headings (MeSH) terms. We grouped the query keywords, which were derived from $\mathrm{MeSH}$ terms and combined through Boolean (AND/OR) operators to identify all relevant studies that matched with our scope and inclusion criteria.

The keywords consisted of MeSH terms such as "safety $[\mathrm{MeSH}]$ " and "artificial intelligence [MeSH]," in combination with narrower MeSH terms (subheadings/related words/phrases) and free text for "artificial intelligence" and "safety." We also included broader key terms to encompass all latent risk factors affecting patient safety. The final search keywords (Figure 3) described below were used to explore all databases.

Figure 3. Medical Subject Heading $(\mathrm{MeSH})$ terms and free text used in the systematic literature review.

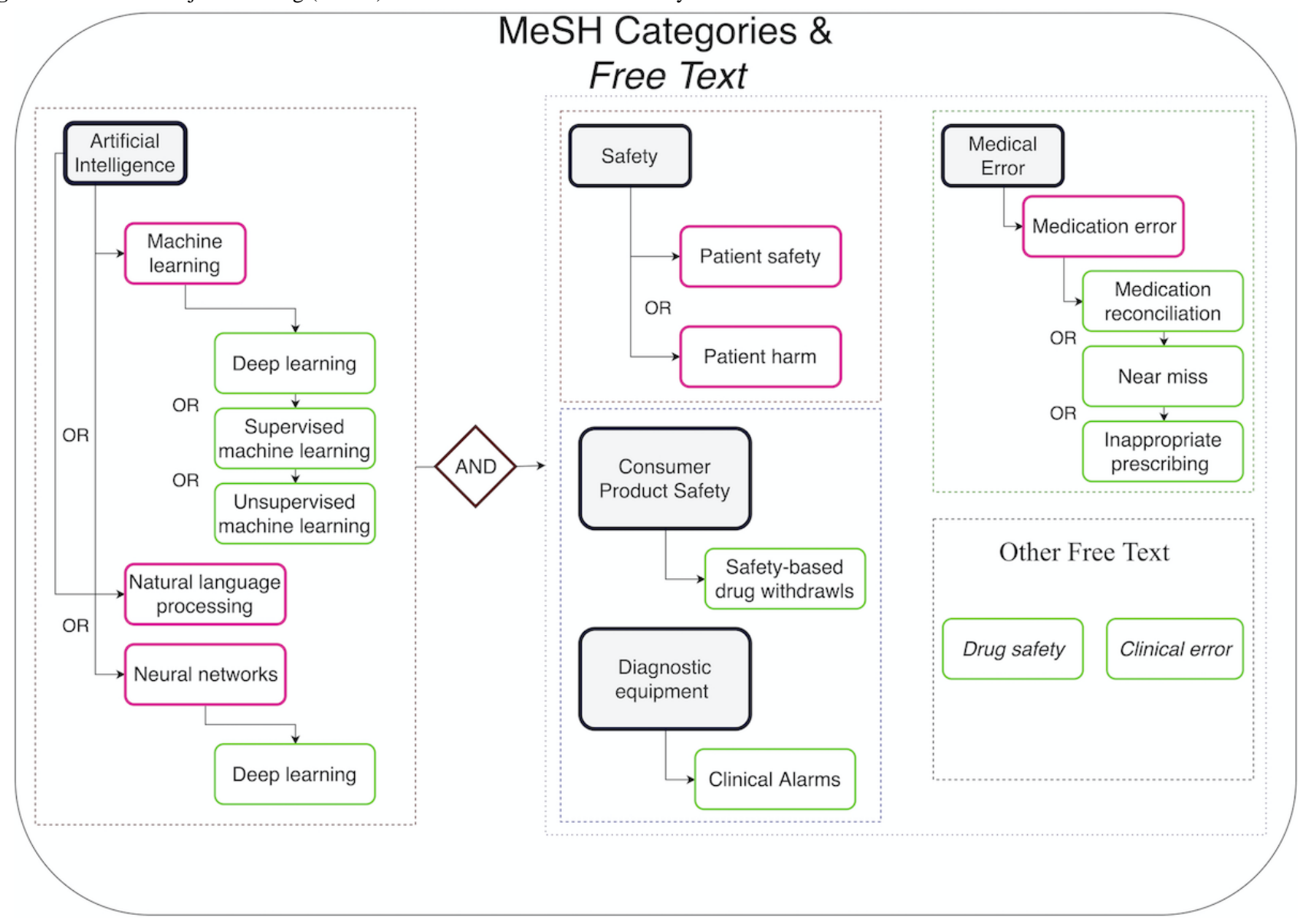

MeSH terms are organized in a tree-like hierarchy, with more specific (narrower) terms arranged beneath broader terms. By default, PubMed includes all of the narrow items in the search in a strategy known as "exploding" the MeSH term [56]. Moreover, the inclusion of MeSH terms optimizes the search strategy [56]. Therefore, the final search query for PubMed was as follows: ("patient safety" OR "safety" [MeSH] OR "drug safety" OR "safety-based Drug withdraws" [MeSH] OR "medication error" OR "Medication Error" [MeSH] OR "medication reconciliation" OR "near miss" OR "inappropriate prescribing" OR "clinical error" OR "Clinical alarms" [MeSH]) AND ("Machine learning" [MeSH] OR "Machine learning" OR "Deep learning" [MeSH] OR "Deep learning" OR "natural language processing" [MeSH] OR "natural language processing").

\section{Inclusion and Exclusion Criteria}

This study focused on peer-reviewed publications satisfying the following two primary conditions: (1) implementation of machine-learning or natural language processing techniques to address patient safety concerns, and (2) discussing or reporting the impact or changes in clinical-level patient safety outcomes. Any papers that failed to satisfy both conditions were excluded from this review. For instance, studies only focusing on developing or evaluating machine-learning models that did not report or discuss changes or impact on clinical-level patient safety outcomes were excluded, as well as studies that used AI beyond our scopes, such as robotics or computer vision. Secondary research such as reviews, commentaries, and conceptual articles was excluded from this study. The search was restricted to papers published in English between January 2009 and August 2019. 


\section{Study Selection and Quality Assurance}

The two authors together reviewed all of the retrieved publications for eligibility. We first screened the publications by studying the titles and abstracts and removed duplications. We then read the full text for the remaining papers and finalized the selection. To minimize any selection bias, all discrepancies were resolved by discussion requiring consensus from both reviewers and the librarian. Before finalizing the list of papers, we consulted our results and searched keywords with the librarian to ensure that no relevant articles were missed.

A data abstraction form was used to record standardized information from each paper as follows: authors, aims, objectives of the study, methods, and findings. Using this form, we categorized each article based on the type of AI algorithm as well as clinical-level patient safety outcomes reported.

\section{Results}

\section{Study Selection}

Figure 4 illustrates the flowchart of the selection process of the articles included in this systematic literature review. The initial search using a set of queries returned 272 publications in PubMed, 1976 publications in PubMed Central, and 248 publications in Web of Science for a total of 2496 articles. We used EndNote X9.3.2 to manage the filtering and duplication removal process. As a first step, we removed duplicates $(\mathrm{n}=101)$, all review/opinion/perspective papers $(n=120)$, and posters or short abstracts $(n=127)$. The two authors then applied a second filtering step by reading abstracts and titles $(n=2148)$. The screening process followed the inclusion and exclusion criteria explained above, resulting in 80 papers eligible for a full-text review. The authors then removed 27 more articles based on the full-text review. Hence, the final number of studies included in the systematic review was 53, with consensus from both authors.

Figure 4. Preferred Reporting Items for Systematic Reviews and Meta-Analysis (PRISMA) flow chart illustrating the process of selecting eligible publications for inclusion in the systematic review. WoS: Web of Science.

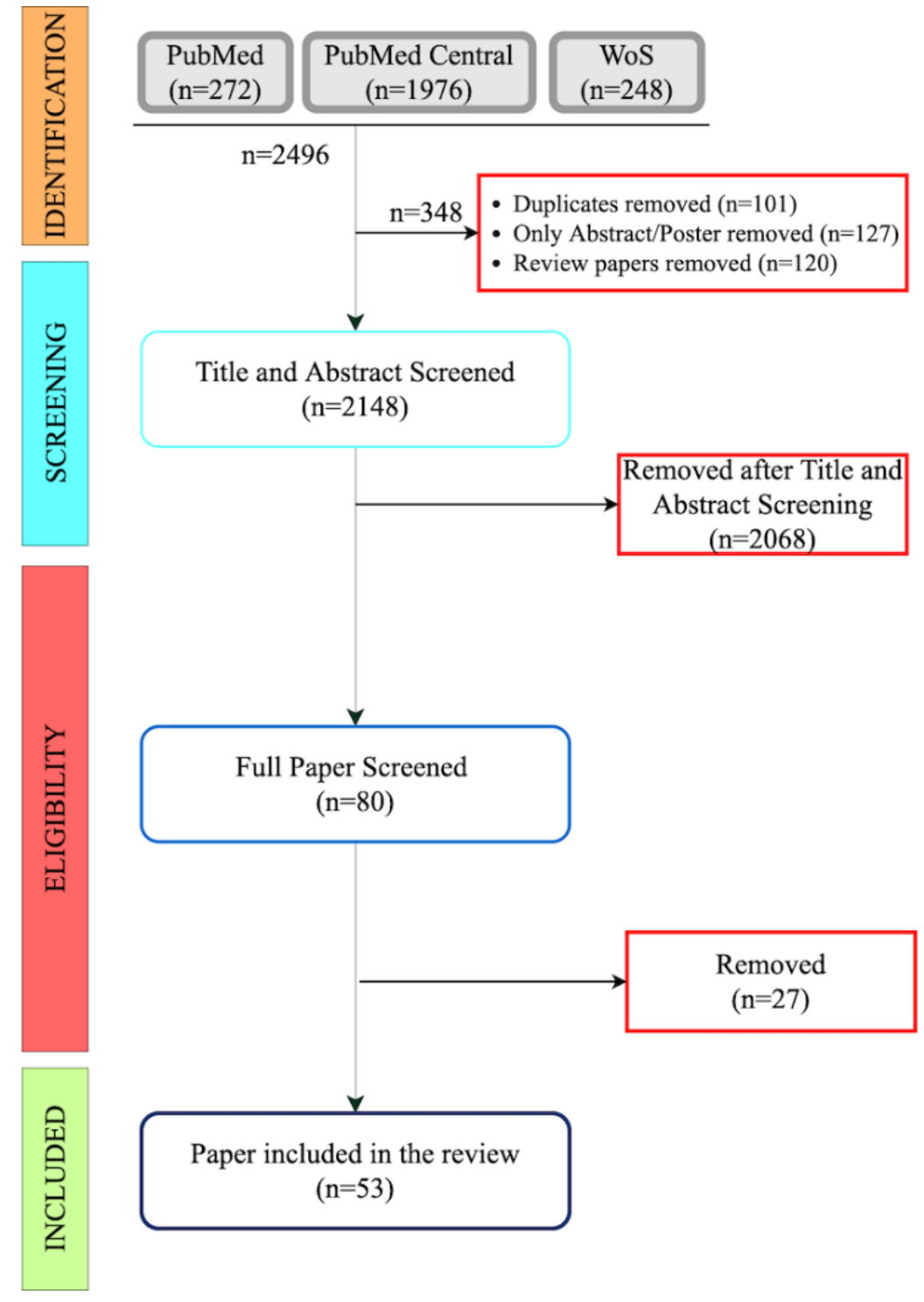


Table 1 outlines all characteristics of the final selected studies $(n=53)$, including the objective of the study and AI methods used, as well as classification of all articles by latent risk factors of patient safety according to (a) Clinical Alarms/Alerts, (b) Clinical Reports, and (c) Adverse Drug Event/Drug Safety. Table 1 also reports the findings obtained regarding changes in patient safety outcomes.

The studies mostly reported positive changes in patient safety outcomes, and in most cases improved or outperformed traditional methods. For instance, AI was successful in minimizing false alarms in several studies and also improved real-time safety reporting systems (Table 1). AI was also able to extract useful information from clinical reports. For example,
AI helped in classifying patients based on their ailments and severity, identified common incidents such as fall risks, delivery delays, hospital information technology errors, bleeding complications, and others that pose risks to patient safety. AI also helped in minimizing adverse drug effects. Further, some studies reported poor outcomes of AI, in which AI's classification accuracy was lower than that of clinicians or existing standards.

Table 2 outlines the performance and accuracy measures of AI models used by the final selected studies, demonstrating the heterogeneity in AI performance measures adopted by different studies. 
Table 1. Evidentiary table of 53 selected publications.

\begin{tabular}{|c|c|c|c|c|}
\hline Reference & Objective & Study theme & $\mathrm{AI}^{\mathrm{a}}$ method & Findings (patient safety outcomes) \\
\hline Chen et al [57] & $\begin{array}{l}\text { To classify alerts as real or } \\
\text { artifacts in online noninva- } \\
\text { sive vital sign data streams } \\
\text { and minimize alarm fa- } \\
\text { tigue and missed true insta- } \\
\text { bility }\end{array}$ & $\begin{array}{l}\text { Clinical } \\
\text { alarms/alerts }\end{array}$ & $\begin{array}{l}\mathrm{KNN}^{\mathrm{b}}, \mathrm{NB}^{\mathrm{c}}, \\
\mathrm{LR}^{\mathrm{d}}, \mathrm{SVM}^{\mathrm{e}}, \mathrm{RF}^{\mathrm{f}}\end{array}$ & $\begin{array}{l}\text { Machine-learning }(\mathrm{ML}) \text { models could distinguish clinically } \\
\text { relevant pulse arterial } \mathrm{O}_{2} \text { saturation, blood pressure, and } \\
\text { respiratory rate from artifacts in an online monitoring dataset } \\
\left(\mathrm{AUC}^{\mathrm{g}}>0.87\right)\end{array}$ \\
\hline Ansari et al [58] & $\begin{array}{l}\text { To minimize false alarms } \\
\text { in the } \mathrm{ICU}^{\mathrm{h}}\end{array}$ & $\begin{array}{l}\text { Clinical } \\
\text { alarms/alerts }\end{array}$ & $\mathrm{MMD}^{\mathrm{i}}, \mathrm{DT}^{\mathrm{j}}$ & $\begin{array}{l}\text { ML algorithm along with MMD was effective in suppressing } \\
\text { false alarms }\end{array}$ \\
\hline Zhang et al [59] & $\begin{array}{l}\text { To minimize the rate of } \\
\text { false critical arrhythmia } \\
\text { alarms }\end{array}$ & $\begin{array}{l}\text { Clinical } \\
\text { alarms/alerts }\end{array}$ & SVM & $\begin{array}{l}\text { SVM reduced false alarm rates. The model gave an overall } \\
\text { true positive rate of } 95 \% \text { and true negative rate of } 85 \%\end{array}$ \\
\hline $\begin{array}{l}\text { Antink et al } \\
{[60]}\end{array}$ & $\begin{array}{l}\text { To reduce false alarms by } \\
\text { using multimodal cardiac } \\
\text { signals recorded from a } \\
\text { patient monitor }\end{array}$ & $\begin{array}{l}\text { Clinical } \\
\text { alarms/alerts }\end{array}$ & $\begin{array}{l}\mathrm{BCT}^{\mathrm{k}}, \mathrm{SVM}, \mathrm{RF}, \\
\mathrm{RDAC}^{\mathrm{l}}\end{array}$ & $\begin{array}{l}\text { A false alarm reduction score of } 65.52 \text { was achieved; } \\
\text { employing an alarm-specific strategy, the model performed } \\
\text { at a true positive rate of } 95 \% \text { and true negative rate of } 78 \% \text {. } \\
\text { False alarms for extreme tachycardia were suppressed with } \\
100 \% \text { sensitivity and specificity }\end{array}$ \\
\hline $\begin{array}{l}\text { Eerikäinen et al } \\
\text { [61] }\end{array}$ & $\begin{array}{l}\text { To classify true and false } \\
\text { cardiac arrhythmia alarms }\end{array}$ & $\begin{array}{l}\text { Clinical alarms or } \\
\text { alerts }\end{array}$ & $\mathrm{RF}$ & $\begin{array}{l}\text { Out of } 5 \text { false alarms, } 4 \text { were suppressed; } 77.39 \% \text { real-time } \\
\text { model accuracy }\end{array}$ \\
\hline $\begin{array}{l}\text { Menard et al } \\
{[62]}\end{array}$ & $\begin{array}{l}\text { Develop a predictive mod- } \\
\text { el that enables } \\
\text { Roche/Genentech Quality } \\
\text { Program Leads oversight } \\
\text { of adverse event reporting } \\
\text { at the program, study, site, } \\
\text { and patient level. }\end{array}$ & $\begin{array}{l}\text { Clinical } \\
\text { alarms/alerts }\end{array}$ & $\begin{array}{l}\text { ML (not dis- } \\
\text { closed) }\end{array}$ & $\begin{array}{l}\text { The ML method identified the sites by risk of underreporting } \\
\text { and enabled real-time safety reporting. The proposed model } \\
\text { had an AUC of } 0.62,0.79 \text {, and } 0.92 \text { for simulation scenarios } \\
\text { of } 25 \%, 50 \% \text {, and } 75 \% \text {, respectively. } \\
\text { This project was part of a broader effort at Roche/Genentech } \\
\text { Product Development Quality to apply advanced analytics } \\
\text { to augment and complement traditional clinical quality assur- } \\
\text { ance approaches }\end{array}$ \\
\hline Segal et al [63] & $\begin{array}{l}\text { To determine the clinical } \\
\text { usefulness of medication } \\
\text { error alerts in a real-life } \\
\text { inpatient setting }\end{array}$ & $\begin{array}{l}\text { Clinical alarms or } \\
\text { alerts }\end{array}$ & Probabilistic ML & $\begin{array}{l}85 \% \text { of the alerts were clinically valid, and } 80 \% \text { were con- } \\
\text { sidered clinically useful; } 43 \% \text { of the alerts caused changes } \\
\text { in subsequent medical orders. Thus, the model detected } \\
\text { medication errors }\end{array}$ \\
\hline Hu et al [64] & $\begin{array}{l}\text { To detect clinical deteriora- } \\
\text { tion }\end{array}$ & $\begin{array}{l}\text { Clinical alarms or } \\
\text { alerts }\end{array}$ & $\mathrm{NN}^{\mathrm{m}}$ & $\begin{array}{l}\text { NN-based model could detect health deterioration such as } \\
\text { heart rate variability with more accuracy than one of the } \\
\text { best-performing early warning scores (ViEWS). The positive } \\
\text { prediction value of NN was } 77.58 \% \text { and the negative predic- } \\
\text { tion value was } 99.19 \%\end{array}$ \\
\hline Kwon et al [65] & $\begin{array}{l}\text { To develop alarm systems } \\
\text { that predict cardiac arrest } \\
\text { early }\end{array}$ & $\begin{array}{l}\text { Clinical alarms or } \\
\text { alerts }\end{array}$ & $\begin{array}{l}\text { RF, LR, DEWS }{ }^{\mathrm{n}} \text {, } \\
\text { and MEWS }\end{array}$ & $\begin{array}{l}\text { The DEWS identified more than } 50 \% \text { of patients with in- } \\
\text { hospital cardiac arrest } 14 \text { hours before the event. It allowed } \\
\text { medical staff to have enough time to intervene. The AUC } \\
\text { and AUPRC }{ }^{\mathrm{p}} \text { of DEWS was } 0.85 \text { and } 0.04 \text {, respectively, and } \\
\text { outperformed MEWS with AUC and AUPC of } 0.60 \text { and } \\
0.003 \text {, respectively; RF with AUC and AUPC of } 0.78 \text { and } \\
0.01 \text {, respectively; and LR with AUC and AUPRC of } 0.61 \\
\text { and } 0.007 \text {, respectively. } \\
\text { DEWS reduced the number of alarms by } 82.2 \%, 13.5 \% \text {, and } \\
42.1 \% \text { compared with the other models at the same sensitiv- } \\
\text { ity }\end{array}$ \\
\hline $\begin{array}{l}\text { Gupta and } \\
\text { Patrick [66] }\end{array}$ & $\begin{array}{l}\text { To classify clinical inci- } \\
\text { dents }\end{array}$ & Clinical Report & $\begin{array}{l}\mathrm{J} 48^{\mathrm{q}} \text {, NB multino- } \\
\text { mial, and SVM }\end{array}$ & $\begin{array}{l}\text { The selected models performed poorly in classifying incident } \\
\text { categories ( } 48.77 \% \text { best, using J48), but performed compar- } \\
\text { atively better in classifying free text ( } 76.49 \% \text { using NB). }\end{array}$ \\
\hline Wang et al [67] & $\begin{array}{l}\text { To identify multiple inci- } \\
\text { dent types from a single } \\
\text { report }\end{array}$ & Clinical Report & $\begin{array}{l}\text { Compares binary } \\
\text { relevance, } \mathrm{CC}^{\mathrm{r}}\end{array}$ & $\begin{array}{l}\text { Binary classifier improved identification of common incident } \\
\text { types: falls, medications, pressure injury, aggression, docu- } \\
\text { mentation problem, and others. Automated identification } \\
\text { enabled safety problems to be detected and addressed in a } \\
\text { more timely manner }\end{array}$ \\
\hline
\end{tabular}




\begin{tabular}{lllll}
\hline Reference & Objective & Study theme & $\mathrm{AI}^{\mathrm{a}}$ method & Findings (patient safety outcomes) \\
\hline Zhou et al [49] & $\begin{array}{l}\text { To extract information } \\
\text { from clinical reports }\end{array}$ & Clinical Report & $\begin{array}{l}\mathrm{SVM}, \mathrm{NB}, \mathrm{RF}, \\
\text { and MLP }\end{array}$ & $\begin{array}{l}\text { ML algorithms identified the medication event originating } \\
\text { stages, event types, and causes, respectively. The models } \\
\text { improved the efficiency of analyzing the medication event } \\
\text { reports and learning from the reports in a timely manner with } \\
\text { (SVM) } F 1 \text { of } 0.792 \text { and (RF) } F 1 \text { of } 0.925\end{array}$ \\
\end{tabular}

Fong et al [68] To analyze patient safety Clinical Report reports

$\begin{array}{lll}\begin{array}{ll}\text { El Messiry et al } \\ {[69]}\end{array} & \begin{array}{l}\text { To analyze patient feed- } \\ \text { back }\end{array} & \text { Clinical Report } \\ \begin{array}{ll}\text { Chondrogiannis } \\ \text { et al [70] }\end{array} & \begin{array}{l}\text { To identify the meaning of } \\ \text { abbreviations used in clini- } \\ \text { cal studies }\end{array} & \text { Clinical Report } \\ \text { Liang and Gong } & \begin{array}{l}\text { To extract information } \\ \text { f71] }\end{array} & \text { Clinical Report }\end{array}$

Ong et al [72] To identify risk events in clinical incident reports

Clinical report

Taggart et al To identify bleeding events Clinical Report [73] using in clinical notes

Denecke et al To minimize any loss of [74] information during a doctor-patient conversation

Evans et al [75] To determine the incident type and the severity of harm outcome

Wang et al [76] To identify the type and severity of patient safety incident reports

Klock et al [47] To understand the root causes of falls and increase learning from fall reports for better prevention of patient falls.

Li et al [77] To stratify patient safety adverse event risk and predict safety problems of individual patients

Murff et al [78] To identify postoperative surgical complications within a comprehensive electronic medical record

Clinical Report

Clinical Report

Clinical Report

Clinical Report
$N L P^{t}$

Pyxis Discrepancy and Pharmacy Delivery Delay were found to be the main two factors affecting patient safety. The NLP models significantly reduced the time required to analyze safety reports

NLP

NLP

Care-related complaints were influenced by money and emotion

Each clinical study document contained about 6.8 abbreviations. Each abbreviation can have 1.25 meanings on average. This helped in identification of acronyms

Multilabel classi- Binary relevance was the best problem transformation algofication methods rithm in the multilabeled classifiers. It provided suggestions on how to implement automated classification of patient safety reports in clinical settings

Text classifiers based on SVM

SVM performed well on datasets with diverse incident types $(85.8 \%)$ and data with patient misidentification $(96.4 \%)$. About $90 \%$ of false positives were found in "near-misses" and $70 \%$ of false negative occurred due to spelling errors

NLP, SVM, Rule-based NLP was better than the ML approach. NLP de$\mathrm{CNN}^{\mathrm{u}}$, and $\mathrm{ET}^{\mathrm{v}} \quad$ tected bleeding complications with $84.6 \%$ specificity, $62.7 \%$ positive predictive value, and $97.1 \%$ negative predictive value. It can thus be used for quality improvement and prevention programs

Clinical Report $\quad$ NLP

Electronic health platform provides an intuitive conversational user interface that patients use to connect to their therapist and self-anamnesis app. The app also allows data sharing among treating therapists

$\mathrm{J} 48$, SVM, and NB

The SVM classifier improved the identification of patient safety incidents. Incident reports containing deaths were most easily classified with an accuracy of $72.82 \%$. The severity classifier was not accurate to replace manual scrutiny

CNN and SVM ensemble

CNN achieved high $F$ scores (>85\%) across all test datasets when identifying common incident types, including falls, medications, pressure injury, and aggression. It improved the process by $11.9 \%$ to $45.10 \%$ across different datasets

SVM, RF, and $\mathrm{RNN}^{\mathrm{W}}$

The model identified high and low scoring fall reports. Most of the patient fall reports scores were between 0.3 and 0.4 , indicating poor quality of reports

Clinical Report

Ensemble-ML

The adverse event risk score at the 0.1 level could identify $57.2 \%$ of adverse events with $26.3 \%$ accuracy from $9.2 \%$ of the validation sample. The adverse event risk score of 0.04 could identify $85.5 \%$ of adverse events

NLP

NLP identified $82 \%$ of acute renal failure cases compared with $38 \%$ for patient safety indicators. Similar results were obtained for venous thromboembolism (59\% vs 46\%), pneumonia (64\% vs 5\%), sepsis ( $89 \%$ vs $34 \%$ ), and postoperative myocardial infarction ( $91 \%$ vs $89 \%$ ) 


\begin{tabular}{|c|c|c|c|c|}
\hline Reference & Objective & Study theme & $\mathrm{AI}^{\mathrm{a}}$ method & Findings (patient safety outcomes) \\
\hline Wang et al [79] & $\begin{array}{l}\text { To automate the identifica- } \\
\text { tion of patient safety inci- } \\
\text { dents in hospitals }\end{array}$ & Clinical Report & $\begin{array}{l}\text { Text-based classi- } \\
\text { fier: LR, SVM }\end{array}$ & $\begin{array}{l}\text { For severity level, the } F \text { score for severity assessment code } \\
\text { (SAC) } 1 \text { (extreme risk) was } 87.3 \text { and } 64 \% \text { for SAC4 (low } \\
\text { risk) on balanced data. With stratified data, a high recall was } \\
\text { achieved for SAC1 ( } 82.8 \%-84 \%) \text {, but precision was poor } \\
(6.8 \%-11.2 \%) \text {. } \\
\text { High-risk incidents (SAC2) and medium-risk incidents } \\
\text { (SAC3) were often misclassified. } \\
\text { Reports about falls, medications, pressure injury, aggression, } \\
\text { and blood tests were identified with high recall and precision }\end{array}$ \\
\hline $\begin{array}{l}\text { Rosenbaum and } \\
\text { Baron [80] }\end{array}$ & $\begin{array}{l}\text { To detect Wrong Blood in } \\
\text { Tube errors and mitigate } \\
\text { patient harm }\end{array}$ & Clinical Report & LR, SVM & $\begin{array}{l}\text { In contrast to the univariate analysis, the best performing } \\
\text { multivariate delta check model (SVM) identified errors with } \\
\text { a high degree of accuracy }(0.97)\end{array}$ \\
\hline McKnight [81] & $\begin{array}{l}\text { To improve the ability to } \\
\text { extract clinical information } \\
\text { from patient safety reports } \\
\text { efficiently }\end{array}$ & Clinical Report & NLP & $\begin{array}{l}\text { The semisupervised model categorized patient safety reports } \\
\text { into their appropriate patient safety topic and avoided over- } \\
\text { laps; } 85 \% \text { of unlabeled reports were assigned correct labels. } \\
\text { It helped NCPS }{ }^{\mathrm{x}} \text { analysts to develop policy and mitigation } \\
\text { decisions }\end{array}$ \\
\hline $\begin{array}{l}\text { Marella et al } \\
\text { [82] }\end{array}$ & $\begin{array}{l}\text { To analyze patient safety } \\
\text { reports describing health } \\
\text { hazards from electronic } \\
\text { health records }\end{array}$ & Clinical Report & $\begin{array}{l}\text { Text mining } \\
\text { based on: NB, } \\
\text { KNN, rule induc- } \\
\text { tion }\end{array}$ & $\begin{array}{l}\text { The NB kernel performed best, with an AUC of } 0.927 \text {, accu- } \\
\text { racy of } 0.855 \text {, and } F \text { score of } 0.877 \text {. } \\
\text { The overall proportion of cases found relevant was compara- } \\
\text { ble between manually and automatically screened cases; } 334 \\
\text { reports identified by the model as relevant were identified } \\
\text { as not relevant, implying a false-positive rate of } 13 \% \text {. } \\
\text { Manual screening identified } 4 \text { incorrect predictions, implying } \\
\text { a false-negative rate of } 29 \%\end{array}$ \\
\hline Ye et al [83] & $\begin{array}{l}\text { To validate a real-time } \\
\text { early warning system to } \\
\text { predict patients at high risk } \\
\text { of inpatient mortality dur- } \\
\text { ing their hospital episodes }\end{array}$ & Clinical Report & $\begin{array}{l}\text { RF, XGB }{ }^{\mathrm{y}} \text {, } \\
\text { boosting SVM, } \\
\mathrm{LASSO}^{\mathrm{z}} \text {, and } \\
\mathrm{KNN}\end{array}$ & $\begin{array}{l}\text { The modified early warning system accurately predicted the } \\
\text { possibility of death for the top } 13.3 \%(34 / 255) \text { of patients at } \\
\text { least } 40.8 \text { hours before death }\end{array}$ \\
\hline Fong et al [84] & $\begin{array}{l}\text { To identify health informa- } \\
\text { tion technology-related } \\
\text { events from patient safety } \\
\text { reports }\end{array}$ & Clinical Report & $\begin{array}{l}\text { Unigram and Bi- } \\
\text { gram LR, SVM }\end{array}$ & $\begin{array}{l}\text { Unigram models performed better than Bigram and combined } \\
\text { models. It identified } \mathrm{HIT}^{\text {aa }} \text {-related events trained on } \text { PSE }^{\text {bb }} \\
\text { free-text descriptions from multiple states and health care } \\
\text { systems. The unigram LR model gave an AUC of } 0.931 \text { and } \\
\text { an } F 1 \text { score of } 0.765 \text {. LR also showed potential to maintain } \\
\text { a faster runtime when more reports are analyzed. The final } \\
\text { HIT model had less complexity and was more easily sharable }\end{array}$ \\
\hline Simon et al [85] & $\begin{array}{l}\text { To establish whether pa- } \\
\text { tients with type } 2 \text { diabetes } \\
\text { can safely use PANDIT } \\
\text { and whether its insulin } \\
\text { dosing advice is clinically } \\
\text { safe }\end{array}$ & Drug safety & PANDIT & $\begin{array}{l}27 \text { out of } 74(36.5 \%) \text { PANDIT advice differed from those } \\
\text { provided by diabetes nurses. However, only one of these } \\
(1.4 \%) \text { was considered unsafe by the panel }\end{array}$ \\
\hline Song et al [86] & $\begin{array}{l}\text { To predict drug-drug inter- } \\
\text { actions }\end{array}$ & Drug safety & SVM & $\begin{array}{l}\text { The } 10 \text { - fold crossvalidation improved the identification of } \\
\text { drug-drug interaction with AUC }>0.97 \text {, which is significantly } \\
\text { greater than the analogously developed ML model }(0.67)\end{array}$ \\
\hline $\begin{array}{l}\text { Hammann et al } \\
{[87]}\end{array}$ & $\begin{array}{l}\text { To identify drugs that } \\
\text { could be suspected of } \\
\text { causing adverse reactions } \\
\text { in the central nervous sys- } \\
\text { tem, liver, and kidneys }\end{array}$ & Drug safety & $\begin{array}{l}\text { CHAID }^{\mathrm{dd}} \text { and } \\
\text { CART }^{\text {ee }}\end{array}$ & $\begin{array}{l}\text { CART exhibited high predictive accuracy of } 78.94 \% \text { for al- } \\
\text { lergic reactions, } 88.69 \% \text { for renal, and } 90.22 \% \text { for the liver. } \\
\text { CHAID model showed a high accuracy of } 89.74 \% \text { for the } \\
\text { central nervous system }\end{array}$ \\
\hline Bean et al [88] & $\begin{array}{l}\text { To predict adverse drug } \\
\text { reactions }\end{array}$ & Drug safety & $\begin{array}{l}\text { LR, SVM, DT, } \\
\text { NLP, own model }\end{array}$ & $\begin{array}{l}\text { The proposed model (own model) outperformed traditional } \\
\text { LR, SVM, DT, and predicted adverse drug reactions with } \\
\text { an AUC of } 0.92\end{array}$ \\
\hline
\end{tabular}




\begin{tabular}{|c|c|c|}
\hline Reference & Objective & Study theme \\
\hline Hu et al [89] & $\begin{array}{l}\text { To predict the appropriate- } \\
\text { ness of initial digoxin } \\
\text { dosage and minimize drug- } \\
\text { drug adverse interactions }\end{array}$ & Drug safety \\
\hline Tang et al [90] & $\begin{array}{l}\text { To identify adverse drug } \\
\text { effects from unstructured } \\
\text { hospital discharge sum- } \\
\text { maries }\end{array}$ & Drug safety \\
\hline $\mathrm{Hu}$ et al [91] & $\begin{array}{l}\text { To predict the dosage of } \\
\text { warfarin }\end{array}$ & Drug safety \\
\hline Hasan et al [92] & $\begin{array}{l}\text { To improve medication } \\
\text { reconciliation task }\end{array}$ & Drug safety \\
\hline $\begin{array}{l}\text { Labovitz et al } \\
\text { [93] }\end{array}$ & $\begin{array}{l}\text { To evaluate the use of a } \\
\text { mobile AI platform on } \\
\text { medication adherence in } \\
\text { stroke patients on anticoag- } \\
\text { ulation therapy }\end{array}$ & Drug safety \\
\hline Long et al [94] & To improve the reconcilia- & Drug safety \\
\hline
\end{tabular}
tion method

$\mathrm{AI}^{\mathrm{a}}$ method Findings (patient safety outcomes)

C4.5, KNN, In the non drug-drug interaction group, the AUC of RF, CART, RF, MLP, MLP, CART, and C4.5 was $0.91,0.81,0.79$, and 0.784 , reand LR spectively; for the drug-drug interaction group, the AUC of RF, CART, MLP, and C4.5 was 0.89, 0.79, 0.77, and 0.77, respectively.

DT-based approaches and MLP can determine the initial dosage of a high-alert digoxin medication, which can increase drug safety in clinical practice

NLP

A total of 33 trial sets were evaluated by the algorithm and reviewed by pharmacovigilance experts. After every 6 trial sets, drug and adverse event dictionaries were updated, and rules were modified to improve the system. The model identified adverse events with $92 \%$ precision and recall

KNN, SVR ${ }^{\mathrm{ff}}$ The proposed model improved warfarin dosage when comNN-BPgg $\mathrm{MT}^{\mathrm{hh}}$ pared to the baseline (mean absolute error 0.394); reduced $\mathrm{NN}-\mathrm{BP}^{\mathrm{g}}, \mathrm{MT}^{\mathrm{h}}$ mean absolute error by $40.04 \%$

LR, KNN

Collaborative filtering identified the top 10 missing drugs about $40 \%$ to $50 \%$ of the time and the therapeutic missing drugs about $50 \%$ to $65 \%$ of the time

Cell phone-based Mean (SD) cumulative adherence based on the AI platform AI platform was $90.5 \%(7.5 \%)$. Plasma drug concentration levels indicated that adherence was $100 \%(15 / 15)$ and $50 \%(6 / 12)$ in the intervention and control groups, respectively

iPad-based soft- All patients completed the task. The software improved ware tool with an reconciliation; all patients identified at least one error in their AI algorithm electronic medical record medication list; 8 of 10 patients reported that they would use the device in the future. The entire team (clinical and patients) liked the device and preferred to use it in the future

ABC4D ABC4D was safe for use as an insulin bolus dosing system. A trend suggesting a reduction in postprandial hypoglycemia was observed.

The median (IQR) number of postprandial hypoglycemia episodes within $6 \mathrm{~h}$ after the meal was $4.5(2.0-8.2)$ in week 1 versus $2.0(0.5-6.5)$ in week $6(P=.10)$. No episodes of severe hypoglycemia occurred during the study

Schiff et al [96] To evaluate the performance and clinical usefulness of medication error alerts generated by an alerting system

Li et al [97] To develop a computerized algorithm for medication discrepancy detection and assess its performance on real-world medication reconciliation data

Carrell et al [98]

To identify evidence of problem opioid use in electronic health records

Tinoco et al [99]
To evaluate the source of information affecting different adverse events
MedAware, prob- $\quad 75 \%$ of the chart-reviewed alerts generated by MedAware abilistic ML were valid from which medication errors were identified. Of these valid alerts, $75.0 \%$ were clinically useful in flagging potential medication errors.

Hybrid system The hybrid algorithm yielded precision $(\mathrm{P})$ of $95.0 \%$, recall consisting of ML $\quad(\mathrm{R})$ of $91.6 \%$, and $F$ value of $93.3 \%$ on medication entity algorithms and identification, and $P=98.7 \%, \mathrm{R}=99.4 \%$, and $F=99.1 \%$ on NLP attribute linkage.

The combination of the hybrid system and medication matching system gave $P=92.4 \%, \mathrm{R}=90.7 \%$, and $F=91.5 \%$, and $P=71.5 \%, \mathrm{R}=65.2 \%$, and $F=68.2 \%$ on classifying the matched and the discrepant medications, respectively

Drug safety

NLP

The NLP-assisted manual review identified an additional $728(3.1 \%)$ patients with evidence of clinically diagnosed problem opioid use in clinical notes.

Drug safety

$\mathrm{CSS}^{\mathrm{jj}}(\mathrm{ML})$
CSS detected more hospital-associated infections than manual chart review (92\% vs 34\%); CSS missed events that were not stored in a coded format 


\begin{tabular}{|c|c|c|c|c|}
\hline Reference & Objective & Study theme & $\mathrm{AI}^{\mathrm{a}}$ method & Findings (patient safety outcomes) \\
\hline Onay et al [100] & $\begin{array}{l}\text { To classify approved drugs } \\
\text { from withdrawn drugs and } \\
\text { thus reduce adverse drug } \\
\text { effects }\end{array}$ & Drug safety & $\begin{array}{l}\text { SVM, Boosted } \\
\text { and Bagged trees } \\
\text { (Ensemble) }\end{array}$ & $\begin{array}{l}\text { The Gaussian SVM model yielded } 78 \% \text { prediction accuracy } \\
\text { for the drug dataset, including all diseases. } \\
\text { The ensemble of bagged tree and linear SVM models in- } \\
\text { volved } 89 \% \text { of the accuracies for psycholeptics and psycho- } \\
\text { analytic drugs }\end{array}$ \\
\hline Cai et al [101] & $\begin{array}{l}\text { To discover drug-drug in- } \\
\text { teractions from the Food } \\
\text { and Drug Administration's } \\
\text { adverse event reporting } \\
\text { system and thus prevent } \\
\text { patient harm }\end{array}$ & Drug safety & $\begin{array}{l}\text { Causal Associa- } \\
\text { tion Rule Discov- } \\
\text { ery (CARD) }\end{array}$ & $\begin{array}{l}\text { CARD demonstrated higher accuracy in identifying known } \\
\text { drug interactions compared to the traditional method ( } 20 \% \\
\text { vs } 10 \% \text { ); } \\
\text { CARD yielded a lower number of drug combinations that } \\
\text { are unknown to interact ( } 50 \% \text { for CARD vs } 79 \% \text { for associ- } \\
\text { ation rule mining). }\end{array}$ \\
\hline $\begin{array}{l}\text { Dandala et al } \\
\text { [102] }\end{array}$ & $\begin{array}{l}\text { To extract adverse drug } \\
\text { events from clinical narra- } \\
\text { tives and automate pharma- } \\
\text { covigilance. }\end{array}$ & Drug safety & $\begin{array}{l}\text { BilSTM }^{\mathrm{kk}}, \mathrm{CRF}- \\
\mathrm{NN}^{11}\end{array}$ & $\begin{array}{l}\text { Joint modeling improved the identification of adverse drug } \\
\text { events from } 0.62 \text { to } 0.65\end{array}$ \\
\hline Dey et al [103] & $\begin{array}{l}\text { To predict and prevent ad- } \\
\text { verse drug reactions at an } \\
\text { early stage to enhance drug } \\
\text { safety }\end{array}$ & Drug safety & Deep learning & $\begin{array}{l}\text { Neural fingerprints from the deep learning model } \\
\text { (AUC }=0.72 \text { ) outperformed all other methods in predicting } \\
\text { adverse drug reactions. } \\
\text { The model identified important molecular substructures that } \\
\text { are associated with specific adverse drug reactions }\end{array}$ \\
\hline Yang et al [104] & $\begin{array}{l}\text { To identify medications, } \\
\text { adverse drug effects, and } \\
\text { their relations with clinical } \\
\text { notes }\end{array}$ & Drug safety & $\begin{array}{l}\text { MADEx, LSTM- } \\
\mathrm{RNN}^{\mathrm{mm}}, \mathrm{CRF}^{\mathrm{nn}} \\
\text { SVM, RF }\end{array}$ & $\begin{array}{l}\text { MADEx achieved the top-three best performances ( } F 1 \text { score } \\
\text { of } 0.8233) \text { for clinical name entity recognition, adverse drug } \\
\text { effect, and relations from clinical texts, which outperformed } \\
\text { traditional methods }\end{array}$ \\
\hline $\begin{array}{l}\text { Chapman et al } \\
\text { [105] }\end{array}$ & $\begin{array}{l}\text { To identify adverse drug } \\
\text { effect symptoms and drugs } \\
\text { in clinical notes }\end{array}$ & Drug safety & NLP & $\begin{array}{l}\text { The micro-averaged } F 1 \text { score was } 80.9 \% \text { for named entity } \\
\text { recognition, } 88.1 \% \text { for relation extraction, and } 61.2 \% \text { for the } \\
\text { integrated systems }\end{array}$ \\
\hline Lian et al [106] & $\begin{array}{l}\text { To detect adverse drug re- } \\
\text { actions }\end{array}$ & Drug safety & $\begin{array}{l}\mathrm{LRM}^{\mathrm{oo}}, \mathrm{BNM}^{\mathrm{pp}} \\
\mathrm{BCP}-\mathrm{NN}^{\mathrm{qq}}\end{array}$ & $\begin{array}{l}\text { Experimental results showed the usefulness of the proposed } \\
\text { pattern discovery method by improving the standard baseline } \\
\text { adverse drug reaction by } 23.83 \%\end{array}$ \\
\hline
\end{tabular}




\begin{tabular}{|c|c|c|c|c|}
\hline Reference & Objective & Study theme & $\mathrm{AI}^{\mathrm{a}}$ method & Findings (patient safety outcomes) \\
\hline $\begin{array}{l}\text { Huang et al } \\
{[107]}\end{array}$ & $\begin{array}{l}\text { To predict adverse drug } \\
\text { effects }\end{array}$ & Drug safety & SVM, LR & $\begin{array}{l}\text { The proposed computational framework showed that an in } \\
\text { silico model built on this framework can achieve satisfactory } \\
\text { cardiotoxicity adverse drug reaction prediction performance } \\
\text { (median AUC }=0.771 \text {, accuracy }=0.675 \text {, sensitivity }=0.632 \text {, } \\
\text { and specificity }=0.789 \text { ). }\end{array}$ \\
\hline
\end{tabular}

${ }^{\mathrm{a}} \mathrm{AI}$ : artificial intelligence.

${ }^{\mathrm{b}} \mathrm{KNN}$ : K-nearest neighbor.

${ }^{\mathrm{c}} \mathrm{NB}$ : naive Bayes.

${ }^{\mathrm{d}} \mathrm{LR}$ : logistic regression.

${ }^{\mathrm{e}} \mathrm{SVM}$ : support vector machine.

${ }^{f} \mathrm{RF}$ : random forest.

${ }^{\mathrm{g}} \mathrm{AUC}$ : area under the curve.

${ }^{\mathrm{h}} \mathrm{ICU}$ : intensive care unit.

${ }^{\mathrm{i}}$ MMD: multimodal section.

${ }^{j_{D T}}$ : decision tree.

${ }^{\mathrm{k}} \mathrm{BCT}$ : binary classification tree.

${ }^{1}$ RDAC: regularized discriminant analysis classifier.

${ }^{\mathrm{m}} \mathrm{NN}$ : neural network.

${ }^{\mathrm{n}}$ DEWS: deep learning-based early warning system.

${ }^{\circ}$ MEWS: modified early warning system.

PAUPRC: area under the precision-recall curve.

${ }^{\mathrm{q}} \mathrm{J} 48$ : decision tree algorithm.

${ }^{\mathrm{r}} \mathrm{CC}$ : closure classifier.

${ }^{\mathrm{s}}$ MLP: multilayer perceptron.

${ }^{\mathrm{t}} \mathrm{NLP}$ : natural language processing.

${ }^{\mathrm{u}} \mathrm{CNN}$ : convolutional neural network.

${ }^{\mathrm{v}}$ ET: extra tree.

${ }^{\mathrm{w}} \mathrm{RNN}$ : recurrent neural network.

${ }^{\mathrm{x}}$ NCPS: National Center for Patient Safety.

${ }^{\mathrm{y}} \mathrm{XGB}$ : extreme gradient boosting.

${ }^{\mathrm{z}}$ LASSO: least absolute shrinkage and selection operator.

${ }^{\text {aa }}$ HIT: health information technology.

${ }^{\mathrm{bb}}$ PSE: patient safety event.

${ }^{\mathrm{cc}}$ PANDIT: Patient Assisting Net-Based Diabetes Insulin Titration.

${ }^{\mathrm{dd}}$ CHAID: Chi square automatic interaction detector.

${ }^{\mathrm{ee}} \mathrm{CART}$ : classification and regression tree.

${ }^{\mathrm{ff}} \mathrm{SVR}$ : support vector regression.

${ }^{\mathrm{gg}} \mathrm{NN}$-BP: neural network-back propagation.

$\mathrm{hh}_{\mathrm{MT}}$ : model tree.

${ }^{i i}$ ABC4D: Advanced Bolus Calculator For Diabetes.

${ }^{\mathrm{jj}} \mathrm{CSS}$ : clinical support system.

${ }^{\mathrm{kk}}$ BiLSTM: bi-long short-term memory neural network.

${ }^{1 l} \mathrm{CRF}-\mathrm{NN}$ : conditional random field neural network.

${ }^{m m}$ LSTM-RNN: long short-term memory-recurrent neural network.

${ }^{\mathrm{nn}} \mathrm{CRF}$ : conditional random field neural network.

${ }^{\mathrm{oo}} \mathrm{LRM}$ : logistic regression probability model.

${ }^{\mathrm{pp}}$ BNM: Bayesian network model.

${ }^{\mathrm{qq}} \mathrm{BCP}-\mathrm{NN}$ : Bayesian confidence propagation neural network. 
Table 2. Performance of artificial intelligence.

\begin{tabular}{|c|c|c|c|c|c|c|c|c|c|}
\hline \multirow[t]{2}{*}{ Reference } & \multirow{2}{*}{$\begin{array}{l}\text { Best model rec- } \\
\text { ommended }\end{array}$} & \multirow{2}{*}{$\begin{array}{l}\text { Comparison/other } \\
\text { models }\end{array}$} & \multicolumn{7}{|c|}{ Performance measures of the best model } \\
\hline & & & Accuracy & AUROC $^{\mathrm{a}}$ & Recall & Specificity & Precision & $F$ measure & other \\
\hline Huanget al [107] & $\mathrm{SVM}^{\mathrm{b}}$ & Logistic regression & 0.675 & 0.771 & 0.632 & 0.789 & $\mathrm{~N} / \mathrm{A}^{\mathrm{c}}$ & N/A & N/A \\
\hline Lian et al [106] & $\begin{array}{l}\text { Ensemble of } \\
\text { three models }\end{array}$ & $\begin{array}{l}\text { Bayesian network } \\
\text { model; likelihood } \\
\text { ratio model; } \\
\text { BCPNN }^{d}\end{array}$ & N/A & N/A & N/A & N/A & N/A & N/A & $\begin{array}{l}\text { Chi- } \\
\text { square } \\
\text { im- } \\
\text { proved } \\
\text { by } \\
28.83 \%\end{array}$ \\
\hline $\begin{array}{l}\text { Chapman et al } \\
\text { [105] }\end{array}$ & $\begin{array}{l}\text { Integrated NLP } \\
\text { with } \mathrm{RF}^{\mathrm{f}} \text { model } \\
\text { for relation extrac- } \\
\text { tion and } \mathrm{CRF}^{\mathrm{g}} \\
\text { model }\end{array}$ & $\begin{array}{l}\text { CRF; RF model for } \\
\text { relation extraction }\end{array}$ & N/A & N/A & N/A & N/A & N/A & 0.612 & N/A \\
\hline Yang et al [104] & $\begin{array}{l}\text { MADEx (long } \\
\text { short-term memo- } \\
\text { ry CRF+SVM) }\end{array}$ & $\begin{array}{l}\mathrm{RNN}^{\mathrm{h}} ; \mathrm{CRF} ; \mathrm{SVM} ; \\
\mathrm{RF}\end{array}$ & N/A & N/A & 0.6542 & N/A & 0.5758 & 0.6125 & N/A \\
\hline Dey et al [103] & $\begin{array}{l}\text { Neural finger- } \\
\text { print (deep learn- } \\
\text { ing) }\end{array}$ & $\begin{array}{l}10 \text { other chemical } \\
\text { fingerprints }\end{array}$ & 0.91 & 0.82 & 0.50 & 0.93 & N/A & 0.400 & N/A \\
\hline $\begin{array}{l}\text { Dandala et al } \\
\text { [102] }\end{array}$ & $\begin{array}{l}\text { BiLSTM }{ }^{\mathrm{i}}+\mathrm{CRF} \\
\text { (joint and exter- } \\
\text { nal resources) }\end{array}$ & $\begin{array}{l}\text { BiLSTM+CRF (se- } \\
\text { quential); BiL- } \\
\text { STM+CRF (joint) }\end{array}$ & N/A & N/A & $\begin{array}{l}0.822 \\
\text { concept } \\
\text { extrac- } \\
\text { tion; } \\
0.855 \text { rela- } \\
\text { tion classi- } \\
\text { fication }\end{array}$ & N/A & $\begin{array}{l}0.846 \\
\text { concept } \\
\text { extrac- } \\
\text { tion; } \\
0.888 \text { rela- } \\
\text { tion classi- } \\
\text { fication }\end{array}$ & $\begin{array}{l}0.83 \text { concept } \\
\text { extraction; } \\
0.87 \text { relation } \\
\text { classification }\end{array}$ & N/A \\
\hline Cai et al [101] & CARD $^{\mathrm{j}}$ & $\begin{array}{l}\text { Association rule } \\
\text { mining }\end{array}$ & N/A & N/A & N/A & N/A & N/A & N/A & $\begin{array}{l}\text { Identify- } \\
\text { ing drug } \\
\text { interac- } \\
\text { tion } \\
20 \%\end{array}$ \\
\hline Onay et al [100] & $\operatorname{LSVM}^{\mathrm{k}}$ & $\begin{array}{l}\text { Boosted and bagged } \\
\text { trees (ensemble) }\end{array}$ & 0.89 & 0.88 & 0.83 & 1.00 & N/A & 0.91 & N/A \\
\hline Tinoco et al [99] & $\begin{array}{l}\text { Computerized } \\
\text { surveillance sys- } \\
\text { tem }\end{array}$ & Manual chart review & N/A & N/A & N/A & N/A & N/A & N/A & 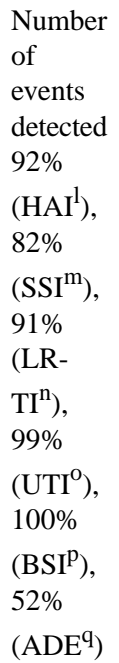 \\
\hline
\end{tabular}




\begin{tabular}{|c|c|c|c|c|c|c|c|c|c|}
\hline \multirow[t]{2}{*}{ Reference } & \multirow{2}{*}{$\begin{array}{l}\text { Best model rec- } \\
\text { ommended }\end{array}$} & \multirow{2}{*}{$\begin{array}{l}\text { Comparison/other } \\
\text { models }\end{array}$} & \multicolumn{7}{|c|}{ Performance measures of the best model } \\
\hline & & & Accuracy & AUROC $^{\mathrm{a}}$ & Recall & Specificity & Precision & $F$ measure & other \\
\hline Carrel et al [98] & $\begin{array}{l}\text { NLP-assisted } \\
\text { manual review }\end{array}$ & Manual chart review & N/A & N/A & N/A & N/A & N/A & N/A & $\begin{array}{l}\text { Identi- } \\
\text { fied } \\
3.1 \% \\
\text { addition- } \\
\text { al pa- } \\
\text { tients } \\
\text { with } \\
\text { opioid } \\
\text { prob- } \\
\text { lems }\end{array}$ \\
\hline Li et al [97] & $\begin{array}{l}\text { NLP-based hy- } \\
\text { brid model }\end{array}$ & $\begin{array}{l}\text { Rule-based method; } \\
\text { CRF }\end{array}$ & N/A & N/A & 0.907 & N/A & 0.924 & 0.915 & N/A \\
\hline Schiff et al [96] & $\begin{array}{l}\text { MedAware, a } \\
\text { probabilistic ma- } \\
\text { chine-learning } \\
\mathrm{CDS}^{\mathrm{r}} \text { system }\end{array}$ & Traditional CDS & 0.75 & N/A & N/A & N/A & N/A & N/A & $\begin{array}{l}75 \% \text { of } \\
\text { the iden- } \\
\text { tified } \\
\text { alerts } \\
\text { were } \\
\text { clinical- } \\
\text { ly mean- } \\
\text { ingful }\end{array}$ \\
\hline Reddy et al [95] & $\begin{array}{l}\mathrm{ABC} 4 \mathrm{D}^{\mathrm{s}} \text { smart- } \\
\text { phone app (based } \\
\text { on } \mathrm{CBR}^{\mathrm{t}} \text {, an } \mathrm{AI}^{\mathrm{u}} \\
\text { technique) }\end{array}$ & N/A & N/A & N/A & N/A & N/A & N/A & N/A & $\begin{array}{l}\mathrm{ABC} 4 \mathrm{D} \\
\text { was su- } \\
\text { perior to } \\
\text { nonadap- } \\
\text { tive bo- } \\
\text { lus cal- } \\
\text { culator } \\
\text { and also } \\
\text { more us- } \\
\text { er } \\
\text { friendly }\end{array}$ \\
\hline Long et al [93] & $\begin{array}{l}\text { AI smartphone } \\
\text { app }\end{array}$ & N/A & N/A & N/A & N/A & N/A & N/A & N/A & $\begin{array}{l}100 \% \\
\text { adher- } \\
\text { ence in } \\
\text { the inter- } \\
\text { vention } \\
\text { group }\end{array}$ \\
\hline Hasan et al [92] & $\begin{array}{l}\text { Co-occurrence } \\
\mathrm{KNN}^{\mathrm{V}} \text { and popu- } \\
\text { lar algorithm }\end{array}$ & $\begin{array}{l}\text { Logistic regression; } \\
\text { KNN; random algo- } \\
\text { rithm; co-occur- } \\
\text { rence; drug populari- } \\
\text { ty }\end{array}$ & N/A & N/A & N/A & N/A & N/A & N/A & $\begin{array}{l}\text { Simple } \\
\text { algo- } \\
\text { rithms } \\
\text { such as } \\
\text { popular } \\
\text { algo- } \\
\text { rithm, } \\
\text { co-oc- } \\
\text { cur- } \\
\text { rence, } \\
\text { and } \\
\text { KNN } \\
\text { per- } \\
\text { formed } \\
\text { better } \\
\text { than } \\
\text { more } \\
\text { com- } \\
\text { plex lo- } \\
\text { gistic re- } \\
\text { gression }\end{array}$ \\
\hline
\end{tabular}




\begin{tabular}{|c|c|c|c|c|c|c|c|c|c|}
\hline \multirow[t]{2}{*}{ Reference } & \multirow{2}{*}{$\begin{array}{l}\text { Best model rec- } \\
\text { ommended }\end{array}$} & \multirow{2}{*}{$\begin{array}{l}\text { Comparison/other } \\
\text { models }\end{array}$} & \multicolumn{7}{|c|}{ Performance measures of the best model } \\
\hline & & & Accuracy & AUROC $^{\mathrm{a}}$ & Recall & Specificity & Precision & $F$ measure & other \\
\hline Hu et al [91] & $\begin{array}{l}\text { Bagged SVR }{ }^{\mathrm{W}} \\
\text { and bagged vot- } \\
\text { ing }\end{array}$ & $\begin{array}{l}\text { MLP }^{\mathrm{x}} ; \text { model tree; } \\
\text { KNN }\end{array}$ & N/A & N/A & N/A & N/A & N/A & N/A & $\begin{array}{l}\text { Mean } \\
\text { absolute } \\
\text { error for } \\
\text { both } \\
0.210\end{array}$ \\
\hline Tang et al [90] & NLP & N/A & N/A & N/A & 0.59 & N/A & 0.75 & N/A & N/A \\
\hline Hu et al [89] & $\mathrm{RF}$ & $\begin{array}{l}\text { C4.5; KNN; } \\
\text { CART }^{\mathrm{y}} ; \mathrm{MLP} ; \text { logis- } \\
\text { tic regression }\end{array}$ & 0.839 & 0.912 & 0.782 & 0.888 & N/A & N/A & N/A \\
\hline Bean et al [88] & Own model & $\begin{array}{l}\text { Logistic regression; } \\
\text { SVM; decision tree; } \\
\text { NLP }\end{array}$ & N/A & 0.92 & N/A & N/A & N/A & N/A & N/A \\
\hline Hamma et al [87] & CART & CART and CHAID $^{\mathrm{Z}}$ & 0.902 & N/A & N/A & N/A & N/A & N/A & $\begin{array}{l}\text { CHAID } \\
\text { outper- } \\
\text { formed } \\
\text { CART } \\
\text { only in } \\
\text { central } \\
\text { nervous } \\
\text { system } \\
\text { classifi- } \\
\text { cation }\end{array}$ \\
\hline Song et al [86] & $\begin{array}{l}\text { Similarity-based } \\
\text { SVM }\end{array}$ & $\begin{array}{l}\text { Analogous machine- } \\
\text { learning algorithms } \\
\text { (not mentioned) }\end{array}$ & N/A & N/A & 0.24 & 0.97 & 0.68 & N/A & N/A \\
\hline Simon et al [85] & PANDIT $^{\text {aa }}$ & Nurses & 0.635 & N/A & N/A & N/A & N/A & N/A & $\begin{array}{l}36.5 \% \\
\text { PAN- } \\
\text { DIT rec- } \\
\text { ommen- } \\
\text { dation } \\
\text { did not } \\
\text { match } \\
\text { with the } \\
\text { nurses; } \\
1.4 \% \text { of } \\
\text { the rec- } \\
\text { ommen- } \\
\text { dations } \\
\text { were un- } \\
\text { safe. }\end{array}$ \\
\hline Fong et al [84] & $\begin{array}{l}\text { Unigram logistic } \\
\text { regression }\end{array}$ & $\begin{array}{l}\text { Unigram, bigram, } \\
\text { and combined logis- } \\
\text { tic regression and } \\
\text { SVM }\end{array}$ & N/A & 0.914 & 0.830 & N/A & 0.838 & 0.765 & $\begin{array}{l}\text { Uni- } \\
\text { gram } \\
\text { SVM } \\
\text { and lo- } \\
\text { gistic re- } \\
\text { gression } \\
\text { were } \\
\text { compa- } \\
\text { rable }\end{array}$ \\
\hline Ye et al [83] & $\mathrm{RF}$ & $\begin{array}{l}\text { Linear and nonlinear } \\
\text { machine-learning al- } \\
\text { gorithms }\end{array}$ & N/A & N/A & N/A & N/A & N/A & N/A & $\begin{array}{l}\text { C-statis- } \\
\text { tic of } \\
0.884\end{array}$ \\
\hline Marella et al [82] & $\begin{array}{l}\text { Naïve Bayes ker- } \\
\text { nel }\end{array}$ & $\begin{array}{l}\text { Naïve Bayes; KNN } \\
\text { and rule induction }\end{array}$ & 0.855 & 0.927 & N/A & N/A & N/A & 0.877 & N/A \\
\hline McKnight [81] & NLP; SELF ${ }^{\mathrm{bb}}$ & N/A & $\begin{array}{l}\text { Labeled } \\
0.52 ; \text { unla- } \\
\text { beled } \\
0.80\end{array}$ & N/A & N/A & N/A & N/A & N/A & N/A \\
\hline
\end{tabular}




\begin{tabular}{|c|c|c|c|c|c|c|c|c|c|}
\hline \multirow[t]{2}{*}{ Reference } & \multirow{2}{*}{$\begin{array}{l}\text { Best model rec- } \\
\text { ommended }\end{array}$} & \multirow{2}{*}{$\begin{array}{l}\text { Comparison/other } \\
\text { models }\end{array}$} & \multicolumn{7}{|c|}{ Performance measures of the best model } \\
\hline & & & Accuracy & AUROC $^{\mathrm{a}}$ & Recall & Specificity & Precision & $F$ measure & other \\
\hline $\begin{array}{l}\text { Rosenbaum and } \\
\text { Baron [80] }\end{array}$ & SVM & Logistic regression & N/A & 0.97 & 0.80 & 0.96 & N/A & N/A & $\begin{array}{l}\text { Positive } \\
\text { predic- } \\
\text { tive val- } \\
\text { ue } 0.52\end{array}$ \\
\hline Wang et al [79] & $\begin{array}{l}\text { Binary SVM with } \\
\text { radial basis func- } \\
\text { tion kernel }\end{array}$ & $\begin{array}{l}\text { Regularized logistic } \\
\text { regression; linear } \\
\text { SVM }\end{array}$ & N/A & N/A & 0.783 & N/A & 0.783 & 0.783 & N/A \\
\hline $\begin{array}{l}\text { Gupta and } \\
\text { Patrick [66] }\end{array}$ & $\begin{array}{l}\text { Naïve Bayes } \\
\text { multinomial }\end{array}$ & $\begin{array}{l}\text { J48; naïve Bayes; } \\
\text { SVM }\end{array}$ & N/A & 0.96 & 0.78 & 0.98 & 0.79 & 0.78 & $\begin{array}{l}\text { Kappa } \\
0.76 ; \\
\text { mean } \\
\text { absolute } \\
\text { error } \\
0.03\end{array}$ \\
\hline Wang et al [67] & $\begin{array}{l}\text { Ensemble classifi- } \\
\text { er chain of SVM } \\
\text { with radial basis } \\
\text { function kernel }\end{array}$ & $\begin{array}{l}\text { Binary relevance of } \\
\text { SVM, classifier } \\
\text { chain of SVM }\end{array}$ & 0.654 & N/A & 0.791 & N/A & 0.689 & 0.736 & $\begin{array}{l}\text { Ham- } \\
\text { ming } \\
\text { loss } \\
0.80\end{array}$ \\
\hline Zhou et al [49] & SVM and RF & $\begin{array}{l}\text { Naïve Bayes and } \\
\text { MLP }\end{array}$ & N/A & N/A & $\begin{array}{l}0.769 \mathrm{SVM} \\
\text { for event } \\
\text { type; } \\
0.927 \mathrm{RF} \\
\text { for even } \\
\text { cause }\end{array}$ & N/A & $\begin{array}{l}0.788 \\
\text { SVM for } \\
\text { event } \\
\text { type; } \\
0.927 \mathrm{RF} \\
\text { for event } \\
\text { cause }\end{array}$ & $\begin{array}{l}0.758 \text { SVM } \\
\text { for event type; } \\
0.925 \text { RF for } \\
\text { event cause }\end{array}$ & N/A \\
\hline Fong et al [68] & NLP with SVM & $\begin{array}{l}\text { NLP with decision } \\
\text { tree }\end{array}$ & 0.990 & 0.960 & 0.920 & 1.00 & 1.000 & 0.960 & N/A \\
\hline $\begin{array}{l}\text { El Messiry et al } \\
\text { [69] }\end{array}$ & NLP & $\begin{array}{l}\text { Scaled linear discrim- } \\
\text { inant analysis; SVM; } \\
\text { LASSO }^{\mathrm{cc}} \text { and elas- } \\
\text { tic-net regularized } \\
\text { generalized linear } \\
\text { models; max en- } \\
\text { tropy; RF; neural } \\
\text { network }\end{array}$ & 0.730 & N/A & 0.770 & 0.696 & N/A & N/A & N/A \\
\hline $\begin{array}{l}\text { Chondrogiannis } \\
\text { et al [70] }\end{array}$ & NLP & N/A & N/A & N/A & N/A & N/A & N/A & N/A & $\begin{array}{l}\text { Model } \\
\text { devel- } \\
\text { oped in } \\
\text { this } \\
\text { study } \\
\text { identi- } \\
\text { fied that } \\
\text { each } \\
\text { clinical } \\
\text { report } \\
\text { contains } \\
\text { about } \\
6.8 \text { ab- } \\
\text { brevia- } \\
\text { tions }\end{array}$ \\
\hline $\begin{array}{l}\text { Liang and Gong } \\
\text { [71] }\end{array}$ & $\begin{array}{l}\text { Naïve Bayes with } \\
\text { binary relevance }\end{array}$ & $\begin{array}{l}\text { SVM; decision rule; } \\
\text { decision tree; KNN }\end{array}$ & N/A & N/A & N/A & N/A & N/A & N/A & $\begin{array}{l}\text { Micro F } \\
\text { measure } \\
0.212\end{array}$ \\
\hline
\end{tabular}




\begin{tabular}{|c|c|c|c|c|c|c|c|c|c|}
\hline \multirow[t]{2}{*}{ Reference } & \multirow{2}{*}{$\begin{array}{l}\text { Best model rec- } \\
\text { ommended }\end{array}$} & \multirow{2}{*}{$\begin{array}{l}\text { Comparison/other } \\
\text { models }\end{array}$} & \multicolumn{7}{|c|}{ Performance measures of the best model } \\
\hline & & & Accuracy & AUROC $^{\mathrm{a}}$ & Recall & Specificity & Precision & $F$ measure & other \\
\hline Ong et al [72] & $\begin{array}{l}\text { Text classifier } \\
\text { with SVM }\end{array}$ & $\begin{array}{l}\text { Text classifier with } \\
\text { naïve Bayes }\end{array}$ & N/A & $\begin{array}{l}0.920 \\
\text { multitype } \\
\text { dataset; } \\
0.980 \text { pa- } \\
\text { tient } \\
\text { misidenti- } \\
\text { fication } \\
\text { dataset }\end{array}$ & $\begin{array}{l}0.830 \\
\text { multitype } \\
\text { dataset; } \\
0.940 \text { pa- } \\
\text { tient } \\
\text { misidenti- } \\
\text { fication } \\
\text { dataset }\end{array}$ & N/A & $\begin{array}{l}0.880 \\
\text { multitype } \\
\text { dataset; } \\
0.990 \text { pa- } \\
\text { tient } \\
\text { misidenti- } \\
\text { fication } \\
\text { dataset }\end{array}$ & $\begin{array}{l}0.860 \text { multi- } \\
\text { type dataset; } \\
0.960 \text { patient } \\
\text { misidentifica- } \\
\text { tion dataset }\end{array}$ & N/A \\
\hline Taggart et al [73] & Rule-based NLP & $\begin{array}{l}\text { SVM; extra trees; } \\
\text { convolutional neural } \\
\text { network }\end{array}$ & N/A & N/A & N/A & 0.846 & N/A & N/A & $\begin{array}{l}\text { Positive } \\
\text { predic- } \\
\text { tive val- } \\
\text { ue } \\
0.627 ; \\
\text { negative } \\
\text { predic- } \\
\text { tive val- } \\
\text { ue } \\
0.971\end{array}$ \\
\hline $\begin{array}{l}\text { Denecke et al } \\
{[74]}\end{array}$ & AIML $^{\mathrm{dd}}$ & N/A & N/A & N/A & N/A & N/A & N/A & N/A & $\begin{array}{l}\text { Mini- } \\
\text { mize in- } \\
\text { forma- } \\
\text { tion loss } \\
\text { during } \\
\text { clinical } \\
\text { visits }\end{array}$ \\
\hline Evans et al [75] & SVM & J48; naïve Bayes & 0.728 & $\begin{array}{l}0.891 \text { inci- } \\
\text { dent type; } \\
0.708 \\
\text { severity } \\
\text { of harm }\end{array}$ & N/A & N/A & N/A & N/A & N/A \\
\hline Wang et al [76] & $\begin{array}{l}\text { Convolutional } \\
\text { neural network }\end{array}$ & SVM & N/A & N/A & N/A & N/A & N/A & 0.850 & N/A \\
\hline Klock et al [47] & SVM and $\mathrm{RNN}^{\mathrm{ee}}$ & $\mathrm{RF}$ & $\begin{array}{l}0.899 \\
\text { SVM; } \\
0.900 \\
\text { RNN }\end{array}$ & N/A & N/A & N/A & N/A & $\begin{array}{l}0.648899 \\
\text { SVM; } 0.889 \\
\text { RNN }\end{array}$ & N/A \\
\hline Li et al [77] & $\begin{array}{l}\text { Ensemble ma- } \\
\text { chine learning } \\
\text { (bagging, boost- } \\
\text { ing, and random } \\
\text { feature method) }\end{array}$ & N/A & N/A & N/A & $\begin{array}{l}0.572 \\
\text { from } 0.10 \\
\text { risk } \\
\text { score; } \\
0.855 \\
\text { from } 0.04 \\
\text { risk score }\end{array}$ & N/A & N/A & N/A & $\begin{array}{l}\text { C-statis- } \\
\text { tic } \\
0.880\end{array}$ \\
\hline Muff et al [78] & NLP & $\begin{array}{l}\text { Patient safety indica- } \\
\text { tors }\end{array}$ & N/A & N/A & 0.770 & 0.938 & N/A & N/A & N/A \\
\hline Kwon et al [65] & $\begin{array}{l}\text { Deep learning- } \\
\text { based early warn- } \\
\text { ing system }\end{array}$ & $\begin{array}{l}\text { Modified early } \\
\text { warning system; RF; } \\
\text { logistic regression }\end{array}$ & N/A & 0.850 & 0.757 & 0.765 & N/A & 1.000 & AUPRC $^{\mathrm{ff}}$ \\
\hline Hu et al [64] & $\begin{array}{l}\text { Neural network } \\
\text { model }\end{array}$ & ViEWS $^{g g}$ & N/A & 0.880 & N/A & N/A & N/A & 0.81 & $\begin{array}{l}\text { Positive } \\
\text { predic- } \\
\text { tive val- } \\
\text { ue } \\
0.726\end{array}$ \\
\hline
\end{tabular}




\begin{tabular}{|c|c|c|c|c|c|c|c|c|c|}
\hline \multirow[t]{2}{*}{ Reference } & \multirow{2}{*}{$\begin{array}{l}\text { Best model rec- } \\
\text { ommended }\end{array}$} & \multirow{2}{*}{$\begin{array}{l}\text { Comparison/other } \\
\text { models }\end{array}$} & \multicolumn{7}{|c|}{ Performance measures of the best model } \\
\hline & & & Accuracy & AUROC $^{\mathrm{a}}$ & Recall & Specificity & Precision & $F$ measure & other \\
\hline Segal et al [63] & $\begin{array}{l}\text { MedAware (a } \\
\left.\text { CDSS }^{\text {hh }}\right)+ \text { EHR }^{\text {ii }}\end{array}$ & Legacy CDS & N/A & N/A & N/A & N/A & N/A & N/A & $\begin{array}{l}\text { Clinical } \\
\text { ly rele- } \\
\text { vant } \\
85 \% \text {, } \\
\text { alert } \\
\text { burden } \\
0.04 \%\end{array}$ \\
\hline Menard et al [62] & $\begin{array}{l}\text { Machine learning } \\
\text { (name not dis- } \\
\text { closed) }\end{array}$ & N/A & N/A & 0.970 & N/A & N/A & N/A & N/A & N/A \\
\hline $\begin{array}{l}\text { Eerikainen et al } \\
\text { [61] }\end{array}$ & $\mathrm{RF}$ & $\begin{array}{l}\text { Binary classification } \\
\text { tree; regularized dis- } \\
\text { criminant analysis } \\
\text { classifier; SVM; RF }\end{array}$ & N/A & N/A & 0.950 & 0.780 & N/A & 0.782 & $\mathrm{~N} / \mathrm{A}$ \\
\hline Antink et al [60] & $\begin{array}{l}\text { Combined (select- } \\
\text { ing the best ma- } \\
\text { chine- learning } \\
\text { algorithm for } \\
\text { each alarm type) }\end{array}$ & $\begin{array}{l}\text { Binary classification } \\
\text { tree; regularized dis- } \\
\text { criminant analysis } \\
\text { classifier; SVM; RF }\end{array}$ & N/A & N/A & 0.950 & 0.780 & N/A & 0.782 & N/A \\
\hline Zhang et al [59] & $\begin{array}{l}\text { Cost-sensitive } \\
\text { SVM }\end{array}$ & N/A & N/A & N/A & 0.950 & 0.850 & N/A & 0.809 & N/A \\
\hline Ansari et al [58] & $\begin{array}{l}\text { Multimodal ma- } \\
\text { chine learning us- } \\
\text { ing decision tree }\end{array}$ & N/A & N/A & N/A & 0.890 & 0.850 & N/A & 0.762 & N/A \\
\hline
\end{tabular}




\begin{tabular}{|c|c|c|c|c|c|c|c|c|c|}
\hline \multirow[t]{2}{*}{ Reference } & \multirow{2}{*}{$\begin{array}{l}\text { Best model rec- } \\
\text { ommended }\end{array}$} & \multirow{2}{*}{$\begin{array}{l}\text { Comparison/other } \\
\text { models }\end{array}$} & \multicolumn{7}{|c|}{ Performance measures of the best model } \\
\hline & & & Accuracy & AUROC $^{\mathrm{a}}$ & Recall & Specificity & Precision & $F$ measure & other \\
\hline Chen et al [57] & $\mathrm{RF}$ & N/A & N/A & 0.870 & N/A & N/A & N/A & N/A & N/A \\
\hline
\end{tabular}

${ }^{a}$ AUROC: area under the receiver operating characteristic curve.

${ }^{\mathrm{b}} \mathrm{SVM}$ : support vector machine.

${ }^{\mathrm{c}} \mathrm{N} / \mathrm{A}$ : not applicable (Not reported).

${ }^{\mathrm{d}}$ BCPNN: Bayesian confidence propagation neural network.

${ }^{\mathrm{e}} \mathrm{NLP}$ : natural language processing.

${ }^{\mathrm{f}} \mathrm{RF}$ : random forest.

${ }^{\mathrm{g}} \mathrm{CRF}$ : conditional random field.

${ }^{\mathrm{h}} \mathrm{RNN}$ : recurrent neural network.

${ }^{\mathrm{i}}$ BiLSTM: Bi-long short-term memory neural network.

${ }^{\mathrm{j}}$ CARD: casual association rule discovery.

${ }^{\mathrm{k}}$ LSVM: linear support vector machine.

${ }^{1}$ HAI: hospital-associated infection.

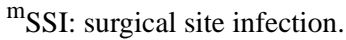

${ }^{\mathrm{n}}$ LRTI: lower respiratory tract infection.

${ }^{\mathrm{o}} \mathrm{UTI}$ : urinary tract infection.

${ }^{\mathrm{p}}$ BSI: bloodstream infection.

${ }^{\mathrm{q}} \mathrm{ADE}$ : adverse drug event.

${ }^{\mathrm{r}} \mathrm{CDS}$ : clinical decision support.

${ }^{\mathrm{S}}$ ABC4D: Advanced Bolus Calculator For Diabetes.

${ }^{\mathrm{t}} \mathrm{CBR}$ : case-based reasoning.

${ }^{\mathrm{u}} \mathrm{AI}$ : artificial intelligence.

${ }^{\mathrm{v}} \mathrm{KNN}$ : K-nearest neighbor.

${ }^{\mathrm{w}} \mathrm{SVR}$ : support vector regression.

${ }^{\mathrm{x}}$ MLP: multilayer perceptron.

${ }^{\mathrm{y}}$ CART: classification and regression tree.

${ }^{\mathrm{z}}$ CHAID: Chi square automatic interaction detector.

${ }^{a a}$ PANDIT: Patient Assisting Net-Based Diabetes Insulin Titration.

${ }^{b b}$ SELF: semisupervised local Fisher discriminant analysis.

${ }^{\mathrm{cc}}$ LASSO: least absolute shrinkage and selection operator.

${ }^{\mathrm{dd}}$ AIML: artificial intelligence markup language.

${ }^{\mathrm{ee}} \mathrm{RNN}$ : recurrent neural network.

${ }^{\mathrm{ff}} \mathrm{AUPRC}$ : area under the precision-recall curve.

${ }^{g g}$ VieWS: VitalPac Early Warning Score.

${ }^{\text {hh }}$ CDSS: clinical decision support system.

${ }^{\mathrm{ii}}$ EHR: electronic health record.

\section{Study Themes and Findings}

\section{Clinical Alarms and Alerts}

Nine publications addressed clinical alarms/alerts using AI techniques. The most widely used method was random forest $(n=5)$ followed by support vector machine $(n=3)$ and neural network/deep learning $(\mathrm{n}=3)$.

Studies under this category used electrocardiogram data from the PhysioNet Challenge public database and PhysioNet MIMIC II database. Five studies focused on reducing false alarm rates arising due to cardiac ailments such as arrhythmia and cardiac arrest in an intensive care unit setting [58-61,65]. The remaining four studies focused on improving the performance of clinical alarms in classifying clinical deterioration such as fluctuation in vital signs [57], predicting adverse events [62], identifying adverse medication events [63], and deterioration of patient health with hematologic malignancies [64].

\section{Clinical Reports}

We identified 21studies concerning clinical reports. Studies in this group primarily focused on extracting information from clinical reports such as safety reports (internal to the hospital), patient feedback, EHR notes, and others typically derived from incident monitoring systems and patient safety organizations. The most widely used method was support vector machine $(n=11)$, followed by natural language processing $(n=7)$ and naïve Bayes $(n=5)$. We also identified decision trees $(n=4)$, deep learning models $(n=3), J 48(n=2)$, and other $(n=9)$ algorithms. 
The majority of articles focused on automating the process of patient safety classifications. These studies used machine learning and natural language processing techniques to classify clinical incidents [66] from the Incident Information Management System and to identify risky incidents $[71,79,81,108]$ in patient safety reports retrieved from different sources, including the university database and the Veterans Affairs National Center for Patient Safety database. Some studies also analyzed medication reports [49] from structured and unstructured data obtained from the patient safety organization, and evaluated patient feedback [69] retrieved from the Patient Advocacy Reporting System developed at Vanderbilt and associated institutions.

Several studies focused on classifying the type and severity of patient safety incident reports using data collected by different sources such as universities [75], and incident reporting systems such as Advanced Incident Management Systems (across Australia) and Riskman [67,75,76]. Others analyzed hospital clinical notes internally (manually annotated by clinicians and a quality committee) and data retrieved from patient safety organizations to identify adverse incidents such as delayed medication [68], fall risks [47,67], near misses, patient misidentification, spelling errors, and ambiguity in clinical notes [109]. One study analyzed clinical study descriptions from clinicaltrials.gov and implemented an AI system to detect all abbreviations and identify their meaning to minimize incorrect interpretations [70]. Another study used inpatient laboratory test reports from Sunquest Laboratory Information System and identified wrong blood in tube errors [80].

Studies used clinical reports from various sources, including patient safety organizations, EHR data from Veterans Health Administration and Berkshire Health Systems, and deidentified notes from the Medical Information Mart for Intensive Care. These studies focused on extracting relevant information $[74,77,82,84]$ to predict bleeding risks among critically ill patients [73], postoperative surgical complications [78], mortality risk [83], and other factors such as lab test results and vital signs [77] influencing patient safety outcomes.

\section{Adverse Drug Events or Drug Safety}

Twenty-three publications were classified under drug safety. These studies primarily addressed adverse effects related to drug reactions. The most widely used method was random forest $(\mathrm{n}=8)$, followed by natural language processing $(\mathrm{n}=7)$ and logistic regression $(n=6)$. Algorithms including natural language processing $(n=5)$, logistic regression $(n=4)$, mobile or web apps $(n=3)$, AI devices $(n=2)$, and others $(n=5)$ were also used.

Studies in this category retrieved data from different repositories such as DrugBank, Side Effect Resource, the Food and Drug Administration (FDA)'s adverse event reporting system, University of Massachusetts Medical School, Observational Medical Outcomes Partnership database, and Human Protein-Protein Interaction database to identify adverse drug interactions and reactions that can potentially negatively influence patient health [86-88,101,102,105-107,110]. Some studies also used AI to predict drug interactions by analyzing EHR data [88], unstructured discharge notes [90], and clinical charts $[99,104]$. One study also used AI to identify drugs that were withdrawn from the commercial markets by the FDA [100].

Some studies used AI to predict the dosage of medicines such as insulin, digoxin, and warfarin $[85,89,91,95]$. AI in drug safety was also used to scan through the hospital's EHR data and identify medication errors (ie, wrong medication prescriptions) [96]. One study used AI to monitor stroke patients and track their medication (anticoagulation) intake [93]. Several studies used AI to predict a medication that a patient could be consuming but was missing from their medication list or health records $[92,94,97]$. Another study used AI to review clinical notes and identify evidence of opioid abuse [98].

\section{Visual Representations of Safety and Chronology of the Studies}

Figure 5 illustrates the details of patient safety issues/outcomes studied and reported under each classified theme using AI algorithms at the clinical level.

Figure 5. Identified factors influencing patient safety outcomes. EHR: electronic health record.

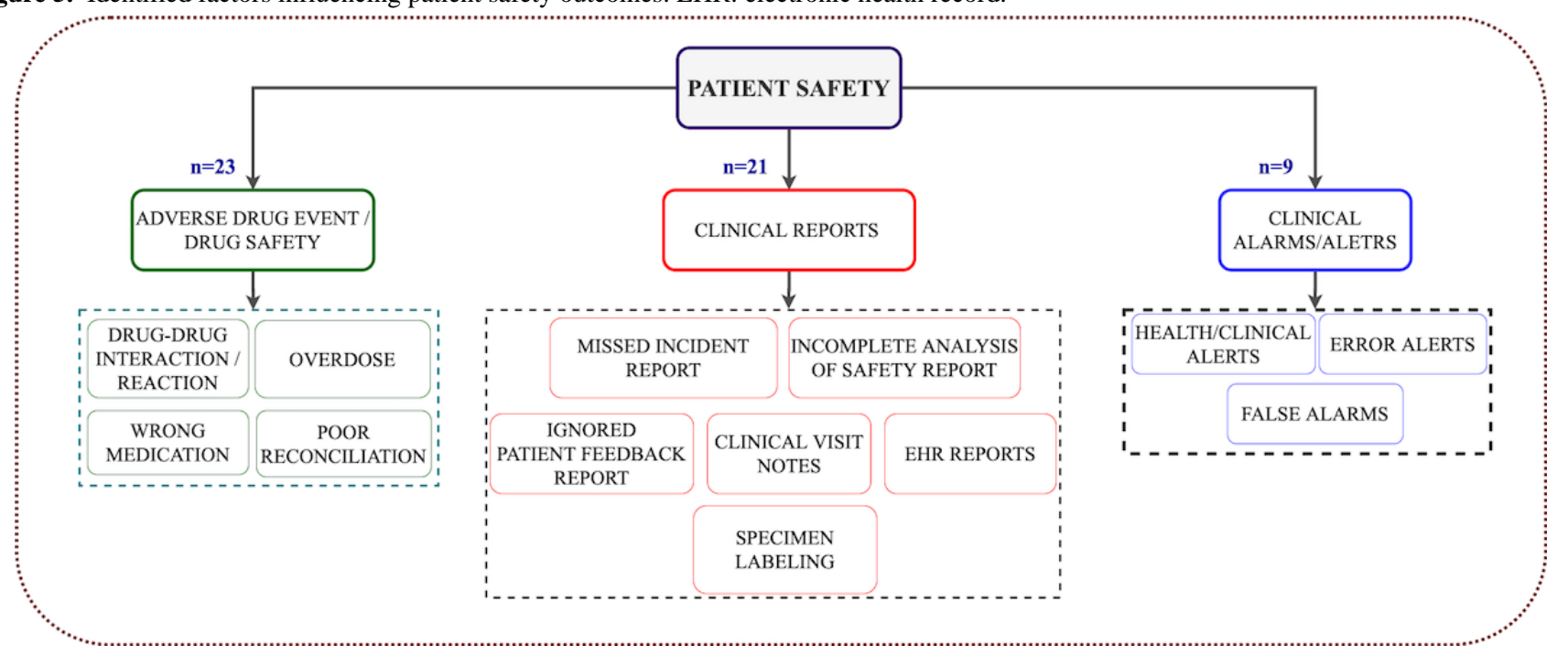


Figure 6 further shows how the application of AI in studies reporting patient safety outcomes in our review evolved over

time between January 2009 and August 2019.

Figure 6. Timeline of artificial intelligence application to address factors influencing patient safety (clinical reports, drug safety, and clinical alarms) between 2009 and August 2019. ABC4D: Advanced Bolus Calculator For Diabetes; AI: artificial intelligence; BCP-NN: Bayesian confidence propagation neural network; BCT: binary classification tree; BiLSTM: bi-long short-term memory neural network; BNM: Bayesian network model; CART: classification and regression tree; CHAID: Chi-square automatic interaction detector; CRF-NN: conditional random field neural network; DEWS: deep learning-based early warning system; DT: decision tree; KNN, K-nearest neighbor; LASSO: least absolute shrinkage and selection operator; LR: logistic regression; LSTM-RNN: long short-term memory-recurrent neural network; MEWS: modified early warning system; ML: machine learning; MLP: multilayer perception; MMD; multimodal detection; MT: model tree; NB: naive Bayes; NLP: natural language processing; NN: neural network; NN-BP: neural network back propagation; PANDIT: Patient Assisting Net-Based Diabetes Insulin Titration; RF: random forest; RNN: recurrent neural network; SVM: support vector machine; SVR, support vector regression; XGB; extreme gradient boosting.

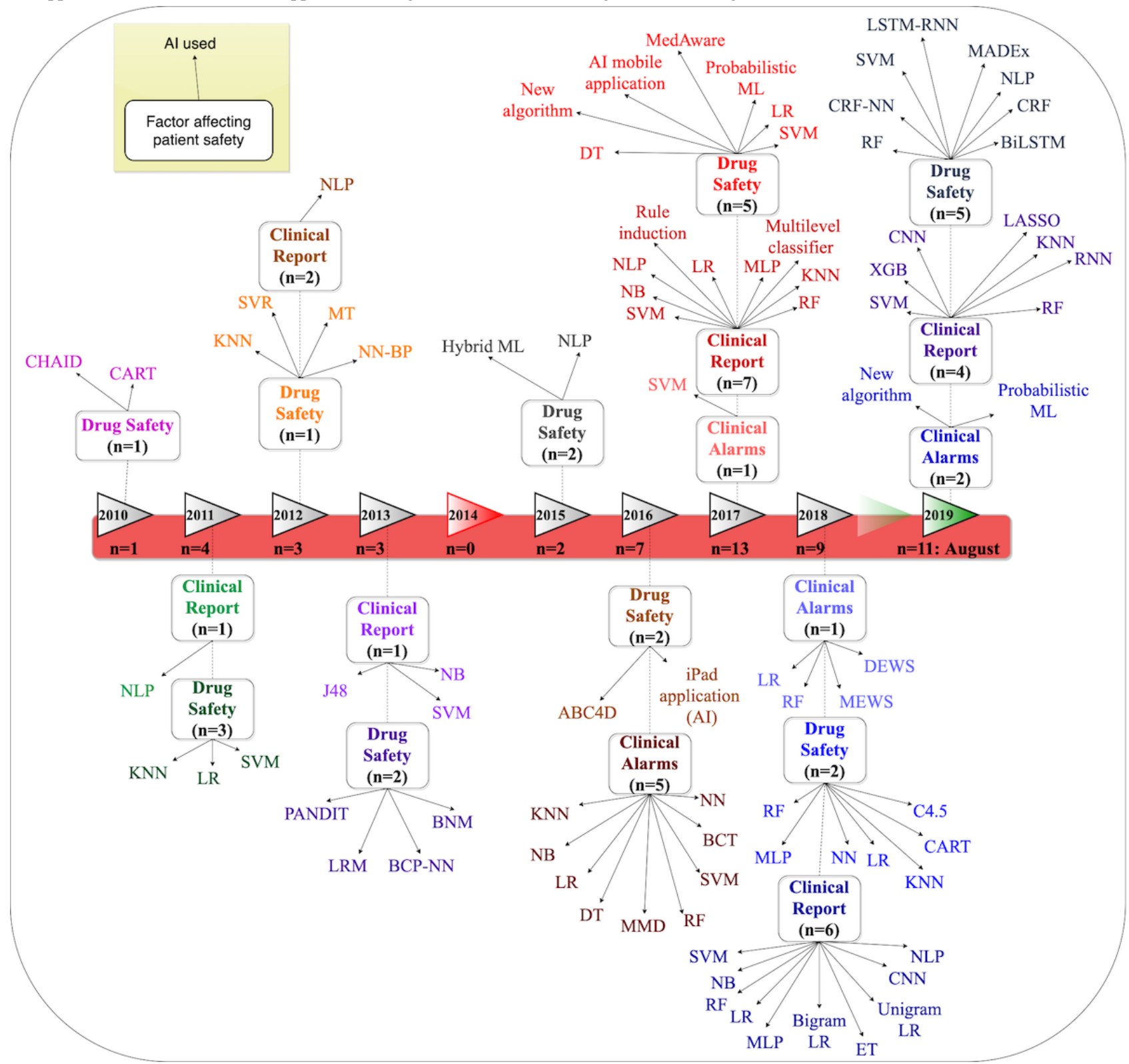

\section{Discussion}

\section{Principal Findings}

Many studies have been conducted to exhibit the analytical performance of AI in health care, particularly as a diagnostic and prognostic tool. To our knowledge, this is the first systematic review exploring and portraying studies that show the influence of AI (machine-learning and natural language processing techniques) on clinical-level patient safety outcomes.
We identified 53 studies within the scope of the review. These 53 studies used 38 different types of AI systems/models to address patient safety outcomes, among which support vector machine $(n=17)$ and natural language processing $(n=12)$ were the most frequently used. Most of the reviewed studies reported positive changes in patient safety outcomes.

Analysis of all studies showed that there is a lack of a standardized benchmark among reported AI models. Despite varying AI performance, most studies have reported a positive impact on safety outcomes (Table 2), thus indicating that safety 
outcomes do not necessarily correlate to AI performance measures [26]. For example, one identified study with an accuracy of 0.63 that implemented Patient Assisting Net-Based Diabetes Insulin Titration (PANDIT) reported a negative impact of AI on safety outcomes. The PANDIT-generated recommendations that did not match with the recommendations of nurses (1.4\% of the recommendations) were identified as unsafe [85]. In contrast, the study implementing natural language processing to extract clinical information from patient safety reports showed a positive impact on patient safety outcomes with accuracy of 0.53 [81]. Similarly, the FDA-approved computer-aided diagnosis of the 1990s, which significantly increased the recall rate of diagnosis, did not improve safety or patient outcomes [111]. According to our review, AI algorithms are rarely scrutinized against a standard of care (clinicians or clinical gold standard). Relying on AI outcomes that have not been evaluated against a standard benchmark that meets clinical requirements can be misleading. A study conducted in 2008 [112] developed and validated an advanced version of the QRISK cardiovascular disease risk algorithm (QRISK2). The study reported improved performance of QRISK2 when compared to its earlier version. However, QRISK2 was not compared against any clinical gold standard. Eight years later, in 2016, The Medicines \& Healthcare Products Regulatory Agency identified an error in the QRISK 2 calculator [113]; QRISK2 underestimated or overestimated the potential risk of cardiovascular disease. The regulatory agency reported that a third of general practitioner surgeries in England might have been affected [113] due to the error in QRISK2. Globally, there are several Standards Development Organizations developing information technology and AI standards to address varying standardization needs in the domain of cloud computing, cybersecurity, and the internet of things [114]. However, there has been minimal effort to standardize AI in the field of health care. Health care comprises multiple departments, each having unique or different requirements (clinical standards). Thus, health care requires so-called "vertical standards," which are standards developed for specific application areas such as drug safety (pharmaceuticals), specific surgeries, outpatients and inpatients with specific health concerns, and emergency departments [114]. In contrast, standards that are not correctly tailored for a specific purpose may hamper patient safety.

Without a standardized benchmark, it becomes challenging to evaluate whether a particular AI system meets clinical requirements (gold standard) or performs significantly better (improves patient safety) or worse (harms patient) than other similar systems in a given health care context. To generate the best possible (highest) performance outcome, AI algorithms may include unreliable confounders into the computing process. For instance, in one study, an algorithm was more likely to classify a skin lesion as malignant if an image (input data) had a ruler in it because the presence of a ruler correlated with an increased likelihood of a cancerous lesion [115]. The presence of surgical skin markings has also been shown to falsely increase a deep-learning model's melanoma probability scores and hence the false-positive rate [116]. Moreover, there has been great emphasis focused on the importance to standardization of AI by developed countries such as the European Union, United States, China, and Japan. For instance, on February 11, 2019, the President of the United States issued an Executive Order (EO 13859) [117] directing federal agencies to actively participate in AI standards development. According to the Center for Data Innovation and The National Institute of Standards and Technology, a standardized AI benchmark can serve as a mechanism to evaluate and compare AI systems [114]. FDA Commissioner Scott Gottlieb acknowledged the importance of AI standardization that can assure that ongoing algorithm changes follow prespecified performance objectives and use a validation process that ensures safety [118].

Another major finding of this review is high heterogeneity in AI reporting. AI systems have been developed to help clinicians in estimating risks and making informed decisions. However, the evidence indicates that the quality of reporting of AI model studies is heterogeneous (not standard). Table 2 demonstrates how different studies that implemented the same AI used different evaluation metrics to measure its performance. Heterogeneity in AI reporting also makes the comparison of algorithms across studies challenging and might cause difficulties in obtaining consensus while attempting to select the best AI for a given situation. Algorithms not only need to be subjected to comparison on the same data that are representative of the target population but also the same evaluation metrics; thus, standardized reporting of AI studies would be beneficial. The current Transparent Reporting of a multivariable prediction model for Individual Prognosis Or Diagnosis (TRIPOD) consists of 22-item checklists that aim to improve the reporting of studies developing or validating a prediction model $[119,120]$. Studies in our review did not use TRIPOD to report findings. The possible reason behind this can be the design of TRIPOD, which focuses on a regression-based prediction model.

However, the explanation and elaboration document provides examples of good reporting methods, which are focused on models developed using regression. Therefore, a new version of the TRIPOD statement that is specific to AI/machine-learning systems (TRIPOD-ML) is in development. It will focus on the introduction of machine-learning prediction algorithms to establish methodological and reporting standards for machine-learning studies in health care [121].

Our findings also identified the need to determine the importance of an AI evaluation metric. In particular, it is important to determine which evaluation metric(s) should be measured in a given health care context. AUROC is considered to be a superior metric for classification accuracy, particularly when unbalanced datasets are used $[122,123]$ because it is unaffected by unbalanced data, which is typical in health care. However, 36 studies in our review did not report AUROC. Evaluation measures such as precision-recall can also reflect model performance accurately [123]; however, only 11 studies in our review evaluated AI based on precision-recall. Using inappropriate measures to evaluate AI performance might impose a threat to patient safety. However, no threat to patient safety due to the use of inappropriate AI evaluation metric was identified in our review. Future studies should report the importance of evaluation metrics and determine which measure (single or multiple measures) is more important and a better representation of patient safety outcomes. More studies are 
needed to explore the evaluation metric(s) that should be considered before recommending an $\mathrm{AI}$ model.

The findings of our review demonstrate that drug safety, followed by the analysis of clinical reports, has been the most common area of interest for the use of AI to address clinical-level patient safety concerns. The wrong medication or improper dosage can result in fatal patient health outcomes and medical malpractice [91]. Of all drug safety concerns, issues related to inappropriate doses of high-alert medications are of great interest to the Joint Commission on Accreditation of Healthcare Organizations [91,124]. Medical errors are reported as the third leading cause of death in the United States. The majority of the papers in our review implemented AI to address drug safety $(n=23)$ concerns, which is one of the most significant contributors to overall medical errors. These publications improved patient safety by identifying adverse drug reactions and preventing incorrect medications or overdoses. Future studies should further explore how to use AI systems on a larger scale to diminish medication errors at hospitals and clinics to save more lives.

Finally, the studies reviewed in this paper have addressed safety issues as identified by the Health Insurance Portability and Accountability Act (HIPAA) and the US Department of Health \& Human Services (HHS). The HIPAA regulations identify risk analysis as part of the administrative safeguard requirement to improve patient safety. The HHS advocates analysis of clinical notes to track, detect, and evaluate potential risks to patients. Many studies $(n=21)$ in our review used AI to identify patient risk from clinical notes. These studies used AI and clinical reports to extract safety-related information such as fall risks, pyxis discrepancies, patient misidentification, patient severity, and postoperative surgical complications. Our findings exhibit how, with the help of AI techniques such as natural language processing, clinical notes and reports have been used as a data source to extract patient data regarding a broad range of safety issues, including clinical notes, discharge notes, and other issues $[69,70,73,84]$. Our review also indicates that AI has the potential to provide valuable insights to treat patients correctly by identifying future health or safety risks [125], to improve health care quality, and reduce clinical errors [126]. Despite being recognized as one of the major factors responsible for fatigue, burnout in clinicians, and patient harm [61,127-129], only 9 studies in our review used AI to improve clinical alarms. Although studies addressing clinical alarms reported positive outcomes by minimizing false alarms and identifying patient health deterioration, the limited number of studies $(n=9)$ addressing these issues shows that the field is still in a nascent period of investigation. Thus, more research is needed to confirm the impact of AI on patient safety outcomes.

\section{Recommendations for Future Research}

Future studies should work toward establishing a gold standard (for various health care contexts/ disease types/problem types) against which AI performance can be measured. Future research, as suggested by Kelly and others in 2019 [119], should also develop a common independent test (preferably for different problem types, drug safety/clinical alarms/clinical reports) using unenriched representative sample data that are not available to train algorithms.

Our review acknowledges that no single measure captures all of the desirable properties of a model, and multiple measures are typically required to summarize model performance. However, different measures are indicative of different types of analytical performance. Future studies should develop a standard framework that can guide clinicians in interpreting the clinical meaning of AI's evaluation metrics before integrating it into the clinical workflow. Future studies should also report a quantifiable measure of AI demonstrating not only its analytical performance but also its impact on patient safety (long and short term), reliability, domain-specific risks, and uncertainty. Additionally, studies should also ensure data standardization.

Health databases or storage systems are often not compatible (integratable) across different hospitals, care providers, or different departments in the same hospital. Data in health care are largely unorganized and unstructured [9,50]. Since the performance of AI heavily depends on data, regulatory bodies should invest in data infrastructure such as standardization of EHRs and integration of different health databases. AI trained on unstructured or biased data might generate misleading results [51]. According to the National Institute of Standards and Technology (NIST), standardized data can make the training data (machine learning input) more visible and usable to authorized users. It can also ensure data quality and improve AI performance.

Most of the safety initiatives implemented in health care over the last decade have been focused on analyzing historical events to learn and evolve [130,131]. The same was also observed in our review. AI models were trained on past data. However, in health care, outcomes are satisfactory because providers make sensible and just-in-time adjustments according to the demands of the situation. Future work should train AI on the critical adjustments made by clinicians, so that AI can adapt to different conditions in the same manner as clinicians.

The integration of AI systems into the health system will alter the role of providers. Ideally, AI systems are expected to assist providers in making faster and more accurate decisions and to deliver personalized patient care. However, lack of appropriate knowledge of using complex AI systems and interpreting their outcome might impose a high cognitive workload on providers. Thus, the medical education system should incorporate necessary AI training for providers so that they can better understand the basic functioning of AI systems and extract clinically meaningful insight from the outcomes of AI.

\section{Limitation of this Review}

This study encompasses publications that matched our inclusion criteria and operational definition of AI and patient safety. In addition, we limited the scope of AI to only machine learning and natural language processing at a clinical level. This review also only included studies published in English in the last 10 years. 


\section{Conclusion}

This systematic review identified critical research gaps that need attention from the scientific community. The majority of the studies in the review have not highlighted significant aspects of AI, such as (a) heterogeneity in AI reporting, (b) lack of a standardized benchmark, and (c) need to determine the importance of AI evaluation metric. The identified flaws of AI systems indicate that further research is needed, as well as the involvement of the FDA and NIST to develop a framework standardizing AI evaluation measures and set a benchmark to ensure patient safety. Thus, our review encourages the health care domain and AI developers to adopt an interdisciplinary and systems approach to study the overall impact of AI on patient safety outcomes and other contexts in health care.

\section{Conflicts of Interest}

None declared.

\section{Multimedia Appendix 1}

Preferred Reporting Items for Systematic Reviews and Meta-Analysis (PRISMA) checklist. [DOC File , 65 KB-Multimedia Appendix 1]

\section{References}

1. World Health Organization. Regional strategy for patient safety in the WHO South-East Asia Region (2016-2025). India: WHO Regional Office for South-East Asia; 2015.

2. Minimal Information Model for Patient Safety Incident Reporting and Learning Systems. World Health Organization. 2016. URL: https://www.who.int/patientsafety/topics/reporting-learning/mim/user-guide/en/ [accessed 2020-06-20]

3. World Health Organization. Provisional agenda item 12.5. Provisional agenda item 12. 2019 Presented at: Seventy-seccond World Health Assembly; May 20-28, 2019; Palais des Nations, Geneva URL: https://apps.who.int/gb/ebwha/pdf_files/ WHA72/A72 JOUR3-en.pdf

4. Liang C, Miao Q, Kang H, Vogelsmeier A, Hilmas T, Wang J, et al. Leveraging Patient Safety Research: Efforts Made Fifteen Years Since To Err Is Human. Stud Health Technol Inform 2019 Aug 21;264:983-987. [doi: 10.3233/SHTI190371] [Medline: $\underline{31438071]}$

5. James JT. A new, evidence-based estimate of patient harms associated with hospital care. J Patient Saf 2013 Sep;9(3):122-128. [doi: 10.1097/PTS.0b013e3182948a69] [Medline: 23860193]

6. Macrae C. Governing the safety of artificial intelligence in healthcare. BMJ Qual Saf 2019 Jun;28(6):495-498. [doi: 10.1136/bmjqs-2019-009484] [Medline: 30979783]

7. Grossman L, Choi S, Collins S, Dykes P, O'Leary K, Rizer M, et al. Implementation of acute care patient portals: recommendations on utility and use from six early adopters. J Am Med Inform Assoc 2018 Apr 01;25(4):370-379. [doi: 10.1093/jamia/ocx074] [Medline: 29040634]

8. McCarthy J, Hayes P. Some philosophical problems from the standpoint of artificial intelligence. In: Meltzer B, Michie D, editors. Machine Intelligence 4. Edinburgh: Edinburgh University Press; 1969:463-502.

9. Hashimoto DA, Rosman G, Rus D, Meireles OR. Artificial Intelligence in Surgery: Promises and Perils. Ann Surg 2018 Jul;268(1):70-76 [FREE Full text] [doi: 10.1097/SLA.0000000000002693] [Medline: 29389679]

10. Bhardwaj R, Nambiar A, Dutta D. A Study of Machine Learning in Healthcare. 2017 Presented at: 2017 IEEE 41 st Annual Computer Software and Applications Conference (COMPSAC); July 4-8, 2017; Turin, Italy. [doi: 10.1109/COMPSAC.2017.164]

11. Kong H. Managing Unstructured Big Data in Healthcare System. Healthc Inform Res 2019 Jan;25(1):1-2 [FREE Full text] [doi: 10.4258/hir.2019.25.1.1] [Medline: $\underline{30788175]}$

12. Lee R, Lober W, Sibley J, Kross E, Engelberg R, Curtis J. Identifying Goals-of-Care Conversations in the Electronic Health Record Using Machine Learning and Natural Language Processing. Am J Resp Crit Care 2020;201(1):A1089. [doi: 10.1164/ajrccm-conference.2019.199.1 meetingabstracts.a1089]

13. Esteva A, Robicquet A, Ramsundar B, Kuleshov V, DePristo M, Chou K, et al. A guide to deep learning in healthcare. Nat Med 2019 Jan;25(1):24-29. [doi: 10.1038/s41591-018-0316-z] [Medline: 30617335]

14. Jiang F, Jiang Y, Zhi H, Dong Y, Li H, Ma S, et al. Artificial intelligence in healthcare: past, present and future. Stroke Vasc Neurol 2017 Dec;2(4):230-243 [FREE Full text] [doi: 10.1136/svn-2017-000101] [Medline: 29507784]

15. Lu H, Li Y, Chen M, Kim H, Serikawa S. Brain Intelligence: Go beyond Artificial Intelligence. Mobile Netw Appl 2017 Sep 21;23(2):368-375. [doi: 10.1007/s11036-017-0932-8]

16. Bahl M, Barzilay R, Yedidia AB, Locascio NJ, Yu L, Lehman CD. High-Risk Breast Lesions: A Machine Learning Model to Predict Pathologic Upgrade and Reduce Unnecessary Surgical Excision. Radiology 2018 Mar;286(3):810-818. [doi: 10.1148/radiol.2017170549] [Medline: 29039725]

17. Guan M, Cho S, Petro R, Zhang W, Pasche B, Topaloglu U. Natural language processing and recurrent network models for identifying genomic mutation-associated cancer treatment change from patient progress notes. JAMIA Open 2019 Apr;2(1):139-149 [FREE Full text] [doi: 10.1093/jamiaopen/ooy061] [Medline: $\underline{\text { 30944913] }}$ 
18. Li Q, Zhao K, Bustamante CD, Ma X, Wong WH. Xrare: a machine learning method jointly modeling phenotypes and genetic evidence for rare disease diagnosis. Genet Med 2019 Sep;21(9):2126-2134 [FREE Full text] [doi: 10.1038/s41436-019-0439-8] [Medline: $\underline{\text { 30675030] }}$

19. Chen H, Engkvist O, Wang Y, Olivecrona M, Blaschke T. The rise of deep learning in drug discovery. Drug Discov Today 2018 Jun;23(6):1241-1250 [FREE Full text] [doi: 10.1016/j.drudis.2018.01.039] [Medline: 29366762]

20. Sahli Costabal F, Matsuno K, Yao J, Perdikaris P, Kuhl E. Machine learning in drug development: Characterizing the effect of 30 drugs on the QT interval using Gaussian process regression, sensitivity analysis, and uncertainty quantification. Comput Meth Appl Mechan Eng 2019 May;348:313-333. [doi: 10.1016/j.cma.2019.01.033]

21. Ekins S, Puhl AC, Zorn KM, Lane TR, Russo DP, Klein JJ, et al. Exploiting machine learning for end-to-end drug discovery and development. Nat Mater 2019 May;18(5):435-441 [FREE Full text] [doi: 10.1038/s41563-019-0338-z] [Medline: 31000803]

22. Banerjee I, Li K, Seneviratne M, Ferrari M, Seto T, Brooks JD, et al. Weakly supervised natural language processing for assessing patient-centered outcome following prostate cancer treatment. JAMIA Open 2019 Apr;2(1):150-159 [FREE Full text] [doi: 10.1093/jamiaopen/ooy057] [Medline: 31032481]

23. Ciervo J, Shen SC, Stallcup K, Thomas A, Farnum MA, Lobanov VS, et al. A new risk and issue management system to improve productivity, quality, and compliance in clinical trials. JAMIA Open 2019 Jul;2(2):216-221 [FREE Full text] [doi: 10.1093/jamiaopen/ooz006] [Medline: $\underline{31984356]}$

24. Ronquillo JG, Erik Winterholler J, Cwikla K, Szymanski R, Levy C. Health IT, hacking, and cybersecurity: national trends in data breaches of protected health information. JAMIA Open 2018 Jul;1(1):15-19 [FREE Full text] [doi: 10.1093/jamiaopen/ooy019] [Medline: $\underline{31984315]}$

25. Dalal AK, Fuller T, Garabedian P, Ergai A, Balint C, Bates DW, et al. Systems engineering and human factors support of a system of novel EHR-integrated tools to prevent harm in the hospital. J Am Med Inform Assoc 2019 Jun 01;26(6):553-560. [doi: 10.1093/jamia/ocz002] [Medline: 30903660]

26. Keane PA, Topol EJ. With an eye to AI and autonomous diagnosis. NPJ Digit Med 2018;1:40 [FREE Full text] [doi: 10.1038/s41746-018-0048-y] [Medline: 31304321$]$

27. Saito T, Rehmsmeier M. The precision-recall plot is more informative than the ROC plot when evaluating binary classifiers on imbalanced datasets. PLoS One 2015 Mar 4;10(3):e0118432 [FREE Full text] [doi: 10.1371/journal.pone.0118432] [Medline: 25738806]

28. Parikh RB, Obermeyer Z, Navathe AS. Regulation of predictive analytics in medicine. Science 2019 Feb 22;363(6429):810-812 [FREE Full text] [doi: 10.1126/science.aaw0029] [Medline: 30792287]

29. Zhang Y, Padman R, Levin JE. Paving the COWpath: data-driven design of pediatric order sets. J Am Med Inform Assoc 2014 Oct;21(e2):e304-e311 [FREE Full text] [doi: 10.1136/amiajnl-2013-002316] [Medline: 24674844]

30. Eloff J, Bella M. Software failures: An overview. In: Software Failure Investigation. Cham: Springer; 2018:7-24.

31. Zhou L, Blackley SV, Kowalski L, Doan R, Acker WW, Landman AB, et al. Analysis of Errors in Dictated Clinical Documents Assisted by Speech Recognition Software and Professional Transcriptionists. JAMA Netw Open 2018 Jul;1(3):e180530 [FREE Full text] [doi: 10.1001/jamanetworkopen.2018.0530] [Medline: 30370424]

32. Salahuddin L, Ismail Z, Hashim UR, Ismail NH, Raja Ikram RR, Abdul Rahim F, et al. Healthcare practitioner behaviours that influence unsafe use of hospital information systems. Health Informatics J 2020 Mar 07;26(1):420-434. [doi: 10.1177/1460458219833090] [Medline: 30843460]

33. Rodziewicz T, Hipskind J. Medical Error. In: StatPearls [Internet]. Treasure Island: StatPearls Publishing; 2019.

34. Topol EJ. High-performance medicine: the convergence of human and artificial intelligence. Nat Med 2019 Jan 7;25(1):44-56. [doi: 10.1038/s41591-018-0300-7] [Medline: 30617339]

35. Chai KEK, Anthony S, Coiera E, Magrabi F. Using statistical text classification to identify health information technology incidents. J Am Med Inform Assoc 2013 Sep 01;20(5):980-985 [FREE Full text] [doi: 10.1136/amiajnl-2012-001409] [Medline: 23666777]

36. Awaysheh A, Wilcke J, Elvinger F, Rees L, Fan W, Zimmerman KL. Review of Medical Decision Support and Machine-Learning Methods. Vet Pathol 2019 Jul;56(4):512-525. [doi: 10.1177/0300985819829524] [Medline: 30866728]

37. Sanchez-Morillo D, Fernandez-Granero MA, Leon-Jimenez A. Use of predictive algorithms in-home monitoring of chronic obstructive pulmonary disease and asthma: A systematic review. Chron Respir Dis 2016 Aug 23;13(3):264-283 [FREE Full text] [doi: 10.1177/1479972316642365] [Medline: 27097638]

38. Pellegrini E, Ballerini L, Hernandez MDCV, Chappell FM, González-Castro V, Anblagan D, et al. Machine learning of neuroimaging for assisted diagnosis of cognitive impairment and dementia: A systematic review. Alzheimers Dement (Amst) 2018;10:519-535 [FREE Full text] [doi: 10.1016/j.dadm.2018.07.004] [Medline: 30364671]

39. Safdar S, Zafar S, Zafar N, Khan NF. Machine learning based decision support systems (DSS) for heart disease diagnosis: a review. Artif Intell Rev 2017 Mar 25;50(4):597-623. [doi: 10.1007/s10462-017-9552-8]

40. Dallora AL, Eivazzadeh S, Mendes E, Berglund J, Anderberg P. Machine learning and microsimulation techniques on the prognosis of dementia: A systematic literature review. PLoS One 2017;12(6):e0179804 [FREE Full text] [doi: 10.1371/journal.pone.0179804] [Medline: 28662070] 
41. Liu X, Faes L, Kale AU, Wagner SK, Fu DJ, Bruynseels A, et al. A comparison of deep learning performance against health-care professionals in detecting diseases from medical imaging: a systematic review and meta-analysis. Lancet Digital Health 2019 Oct;1(6):e271-e297. [doi: 10.1016/s2589-7500(19)30123-2]

42. Chen M, Hao Y, Hwang K, Wang L, Wang L. Disease Prediction by Machine Learning Over Big Data From Healthcare Communities. IEEE Access 2017;5:8869-8879. [doi: 10.1109/ACCESS.2017.2694446]

43. Yeh DH, Tam S, Fung K, MacNeil SD, Yoo J, Winquist E, et al. Transoral robotic surgery vs. radiotherapy for management of oropharyngeal squamous cell carcinoma - A systematic review of the literature. Eur J Surg Oncol 2015 Dec;41(12):1603-1614. [doi: 10.1016/j.ejso.2015.09.007] [Medline: 26461255]

44. Ficarra V, Novara G, Rosen RC, Artibani W, Carroll PR, Costello A, et al. Systematic review and meta-analysis of studies reporting urinary continence recovery after robot-assisted radical prostatectomy. Eur Urol 2012 Sep;62(3):405-417. [doi: 10.1016/j.eururo.2012.05.045] [Medline: 22749852]

45. Dowthwaite SA, Franklin JH, Palma DA, Fung K, Yoo J, Nichols AC. The role of transoral robotic surgery in the management of oropharyngeal cancer: a review of the literature. ISRN Oncol 2012;2012:945162 [FREE Full text] [doi: 10.5402/2012/945162] [Medline: 22606380]

46. Karthik K, Colegate-Stone T, Dasgupta P, Tavakkolizadeh A, Sinha J. Robotic surgery in trauma and orthopaedics: a systematic review. Bone Joint J 2015 Mar;97-B(3):292-299. [doi: 10.1302/0301-620X.97B3.35107] [Medline: 25737510]

47. Klock M, Kang H, Gong Y. Scoring Patient Fall Reports Using Quality Rubric and Machine Learning. Stud Health Technol Inform 2019 Aug 21;264:639-643. [doi: 10.3233/SHTI190301] [Medline: 31438002]

48. Wang E, Kang H, Gong Y. Generating a Health Information Technology Event Database from FDA MAUDE Reports. Stud Health Technol Inform 2019 Aug 21;264:883-887. [doi: 10.3233/SHTI190350] [Medline: 31438051]

49. Zhou S, Kang H, Yao B, Gong Y. An automated pipeline for analyzing medication event reports in clinical settings. BMC Med Inform Decis Mak 2018 Dec 07;18(Suppl 5):113 [FREE Full text] [doi: 10.1186/s12911-018-0687-6] [Medline: $\underline{30526590]}$

50. Maddox TM, Rumsfeld JS, Payne PRO. Questions for Artificial Intelligence in Health Care. JAMA 2019 Jan 01;321(1):31-32. [doi: 10.1001/jama.2018.18932] [Medline: 30535130]

51. Davatzikos C. Machine learning in neuroimaging: Progress and challenges. Neuroimage 2019 Aug 15;197:652-656 [FREE Full text] [doi: 10.1016/j.neuroimage.2018.10.003] [Medline: 30296563]

52. Gianfrancesco MA, Tamang S, Yazdany J, Schmajuk G. Potential Biases in Machine Learning Algorithms Using Electronic Health Record Data. JAMA Intern Med 2018 Nov 01;178(11):1544-1547 [FREE Full text] [doi:

10.1001/jamainternmed.2018.3763] [Medline: 30128552]

53. Goldstein BA, Navar AM, Pencina MJ, Ioannidis JPA. Opportunities and challenges in developing risk prediction models with electronic health records data: a systematic review. J Am Med Inform Assoc 2017 Jan;24(1):198-208 [RREE Full text] [doi: 10.1093/jamia/ocw042] [Medline: 27189013]

54. Powers EM, Shiffman RN, Melnick ER, Hickner A, Sharifi M. Efficacy and unintended consequences of hard-stop alerts in electronic health record systems: a systematic review. J Am Med Inform Assoc 2018 Nov 01;25(11):1556-1566 [FREE Full text] [doi: 10.1093/jamia/ocy112] [Medline: 30239810]

55. Choudhury A, Asan O. Patient SafetyArtificial Intelligence. OSF. URL: https://osf.io/vqjk5/ [accessed 2019-09-15]

56. Ecker ED, Skelly AC. Conducting a winning literature search. Evid Based Spine Care J 2010 May;1(1):9-14 [FREE Full text] [doi: 10.1055/s-0028-1100887] [Medline: 23544018]

57. Chen L, Dubrawski A, Wang D, Fiterau M, Guillame-Bert M, Bose E, et al. Using Supervised Machine Learning to Classify Real Alerts and Artifact in Online Multisignal Vital Sign Monitoring Data. Crit Care Med 2016 Jul;44(7):e456-e463 [FREE Full text] [doi: 10.1097/CCM.0000000000001660] [Medline: 26992068]

58. Ansari S, Belle A, Ghanbari H, Salamango M, Najarian K. Suppression of false arrhythmia alarms in the ICU: a machine learning approach. Physiol Meas 2016 Aug;37(8):1186-1203. [doi: 10.1088/0967-3334/37/8/1186] [Medline: 27454017]

59. Zhang Q, Chen X, Fang Z, Zhan Q, Yang T, Xia S. Reducing false arrhythmia alarm rates using robust heart rate estimation and cost-sensitive support vector machines. Physiol Meas 2017 Feb;38(2):259-271. [doi: 10.1088/1361-6579/38/2/259] [Medline: 28099159]

60. Antink CH, Leonhardt S, Walter M. Reducing false alarms in the ICU by quantifying self-similarity of multimodal biosignals. Physiol Meas 2016 Aug;37(8):1233-1252. [doi: 10.1088/0967-3334/37/8/1233] [Medline: 27454256]

61. Eerikäinen LM, Vanschoren J, Rooijakkers MJ, Vullings R, Aarts RM. Reduction of false arrhythmia alarms using signal selection and machine learning. Physiol Meas 2016 Aug 25;37(8):1204-1216. [doi: 10.1088/0967-3334/37/8/1204] [Medline: 27454128]

62. Ménard T, Barmaz Y, Koneswarakantha B, Bowling R, Popko L. Enabling Data-Driven Clinical Quality Assurance: Predicting Adverse Event Reporting in Clinical Trials Using Machine Learning. Drug Saf 2019 Sep 23;42(9):1045-1053 [FREE Full text] [doi: 10.1007/s40264-019-00831-4] [Medline: 31123940]

63. Segal G, Segev A, Brom A, Lifshitz Y, Wasserstrum Y, Zimlichman E. Reducing drug prescription errors and adverse drug events by application of a probabilistic, machine-learning based clinical decision support system in an inpatient setting. J Am Med Inform Assoc 2019 Dec 01;26(12):1560-1565. [doi: 10.1093/jamia/ocz135] [Medline: 31390471] 
64. Hu SB, Wong DJL, Correa A, Li N, Deng JC. Prediction of Clinical Deterioration in Hospitalized Adult Patients with Hematologic Malignancies Using a Neural Network Model. PLoS One 2016;11(8):e0161401 [FREE Full text] [doi: 10.1371/journal.pone.0161401] [Medline: 27532679]

65. Kwon J, Lee Y, Lee Y, Lee S, Park J. An Algorithm Based on Deep Learning for Predicting In-Hospital Cardiac Arrest. J Am Heart Assoc 2018 Jun 26;7(13):e008678 [FREE Full text] [doi: 10.1161/JAHA.118.008678] [Medline: 29945914]

66. Gupta J, Patrick J. Automated validation of patient safety clinical incident classification: macro analysis. Stud Health Technol Inform 2013;188:52-57. [Medline: 23823288]

67. Wang Y, Coiera EW, Runciman W, Magrabi F. Automating the Identification of Patient Safety Incident Reports Using Multi-Label Classification. : IOS Press; 2017 Presented at: Precision Healthcare Through Informatics: Proceedings of the 16th World Congress on Medical and Health Informatics; August 21-25, 2017; Hangzhou, China p. 609-613.

68. Fong A, Harriott N, Walters DM, Foley H, Morrissey R, Ratwani RR. Integrating natural language processing expertise with patient safety event review committees to improve the analysis of medication events. Int J Med Inform 2017 Aug;104:120-125. [doi: 10.1016/j.ijmedinf.2017.05.005] [Medline: 28529113]

69. ElMessiry A, Zhang Z, Cooper W, Catron T, Karrass J, Singh M, editors. Leveraging sentiment analysis for classifying patient complaints. 2017 Presented at: Proceedings of the 8th ACM International Conference on Bioinformatics, Computational Biology,Health Informatics; 2017; Boston. [doi: 10.1145/3107411.3107421]

70. Chondrogiannis E, Andronikou V, Varvarigou T, Karanastasis E, editors. Semantically-Enabled Context-Aware Abbreviations Expansion in the Clinical Domain. 2017 Presented at: Proceedings of the 9th International Conference on Bioinformatics Biomedical Technology; 2017; Washington DC. [doi: 10.1145/3093293.3093304]

71. Liang C, Gong Y. Automated Classification of Multi-Labeled Patient Safety Reports: A Shift from Quantity to Quality Measure. Stud Health Technol Inform 2017;245:1070-1074. [Medline: 29295266]

72. Ong M, Magrabi F, Coiera E. Automated identification of extreme-risk events in clinical incident reports. J Am Med Inform Assoc 2012 Jun;19(e1):e110-e118 [FREE Full text] [doi: 10.1136/amiajnl-2011-000562] [Medline: 22237865]

73. Taggart M, Chapman WW, Steinberg BA, Ruckel S, Pregenzer-Wenzler A, Du Y, et al. Comparison of 2 Natural Language Processing Methods for Identification of Bleeding Among Critically Ill Patients. JAMA Netw Open 2018 Oct 05;1(6):e183451 [FREE Full text] [doi: 10.1001/jamanetworkopen.2018.3451] [Medline: 30646240]

74. Denecke K, Lutz HS, Pöpel A, May R, editors. Talking to ana: A mobile self-anamnesis application with conversational user interface. 2018 Presented at: Proceedings of the 2018 International Conference on Digital Health; 2018; Lyon. [doi: 10.1145/3194658.3194670]

75. Evans HP, Anastasiou A, Edwards A, Hibbert P, Makeham M, Luz S, et al. Automated classification of primary care patient safety incident report content and severity using supervised machine learning (ML) approaches. Health Informatics J 2019 Mar 07:1460458219833102. [doi: 10.1177/1460458219833102] [Medline: $\underline{\text { 30843455] }}$

76. Wang Y, Coiera E, Magrabi F. Using convolutional neural networks to identify patient safety incident reports by type and severity. J Am Med Inform Assoc 2019 Dec 01;26(12):1600-1608. [doi: 10.1093/jamia/ocz146] [Medline: 31730700]

77. Li M, Ladner D, Miller S, Classen D. Identifying hospital patient safety problems in real-time with electronic medical record data using an ensemble machine learning model. Int J Clin Med Inform 2018;1(1):43-58.

78. Murff HJ, FitzHenry F, Matheny ME, Gentry N, Kotter KL, Crimin K, et al. Automated identification of postoperative complications within an electronic medical record using natural language processing. JAMA 2011 Aug 24;306(8):848-855. [doi: 10.1001/jama.2011.1204] [Medline: 21862746]

79. Wang Y, Coiera E, Runciman W, Magrabi F. Using multiclass classification to automate the identification of patient safety incident reports by type and severity. BMC Med Inform Decis Mak 2017 Jun 12;17(1):84 [FREE Full text] [doi: 10.1186/s12911-017-0483-8] [Medline: 28606174]

80. Rosenbaum M, Baron J. Using Machine Learning-Based Multianalyte Delta Checks to Detect Wrong Blood in Tube Errors. Am J Clin Pathol 2018 Oct 24;150(6):555-566. [doi: 10.1093/ajcp/aqy085] [Medline: 30169595]

81. McKnight SD. Semi-supervised classification of patient safety event reports. J Patient Saf 2012 Jun;8(2):60-64. [doi: 10.1097/PTS.0b013e31824ab987] [Medline: 22543364]

82. Marella WM, Sparnon E, Finley E. Screening Electronic Health Record-Related Patient Safety Reports Using Machine Learning. J Patient Saf 2017 Mar;13(1):31-36. [doi: 10.1097/PTS.0000000000000104] [Medline: 24721977]

83. Ye C, Wang O, Liu M, Zheng L, Xia M, Hao S, et al. A Real-Time Early Warning System for Monitoring Inpatient Mortality Risk: Prospective Study Using Electronic Medical Record Data. J Med Internet Res 2019 Jul 05;21(7):e13719 [FREE Full text] [doi: 10.2196/13719] [Medline: $\underline{31278734]}$

84. Fong A, Adams KT, Gaunt MJ, Howe JL, Kellogg KM, Ratwani RM. Identifying health information technology related safety event reports from patient safety event report databases. J Biomed Inform 2018 Oct;86:135-142 [FREE Full text] [doi: 10.1016/j.jbi.2018.09.007] [Medline: 30213556]

85. Simon ACR, Holleman F, Gude WT, Hoekstra JBL, Peute LW, Jaspers MWM, et al. Safety and usability evaluation of a web-based insulin self-titration system for patients with type 2 diabetes mellitus. Artif Intell Med 2013 Sep;59(1):23-31. [doi: 10.1016/j.artmed.2013.04.009] [Medline: 23735522] 
86. Song D, Chen Y, Min Q, Sun Q, Ye K, Zhou C, et al. Similarity-based machine learning support vector machine predictor of drug-drug interactions with improved accuracies. J Clin Pharm Ther 2019 Apr 18;44(2):268-275. [doi: 10.1111/jcpt.12786] [Medline: $\underline{30565313}$ ]

87. Hammann F, Gutmann H, Vogt N, Helma C, Drewe J. Prediction of adverse drug reactions using decision tree modeling. Clin Pharmacol Ther 2010 Jul 10;88(1):52-59. [doi: 10.1038/clpt.2009.248] [Medline: 20220749]

88. Bean DM, Wu H, Iqbal E, Dzahini O, Ibrahim ZM, Broadbent M, et al. Knowledge graph prediction of unknown adverse drug reactions and validation in electronic health records. Sci Rep 2017 Nov 27;7(1):16416. [doi: 10.1038/s41598-017-16674-x] [Medline: 29180758]

89. Hu Y, Tai C, Tsai C, Huang M. Improvement of Adequate Digoxin Dosage: An Application of Machine Learning Approach. J Healthc Eng 2018;2018:3948245. [doi: 10.1155/2018/3948245] [Medline: 30210752]

90. Tang Y, Yang J, Ang PS, Dorajoo SR, Foo B, Soh S, et al. Detecting adverse drug reactions in discharge summaries of electronic medical records using Readpeer. Int J Med Inform 2019 Aug;128:62-70. [doi: 10.1016/j.ijmedinf.2019.04.017] [Medline: 31160013]

91. Hu Y, Wu F, Lo C, Tai C. Predicting warfarin dosage from clinical data: a supervised learning approach. Artif Intell Med 2012 Sep;56(1):27-34. [doi: 10.1016/j.artmed.2012.04.001] [Medline: 22537823]

92. Hasan S, Duncan GT, Neill DB, Padman R. Automatic detection of omissions in medication lists. J Am Med Inform Assoc 2011 Jul 01;18(4):449-458 [FREE Full text] [doi: 10.1136/amiajnl-2011-000106] [Medline: 21447497]

93. Labovitz DL, Shafner L, Reyes Gil M, Virmani D, Hanina A. Using Artificial Intelligence to Reduce the Risk of Nonadherence in Patients on Anticoagulation Therapy. Stroke 2017 May;48(5):1416-1419 [FREE Full text] [doi: 10.1161/STROKEAHA.116.016281] [Medline: 28386037]

94. Long J, Yuan MJ, Poonawala R. An Observational Study to Evaluate the Usability and Intent to Adopt an Artificial Intelligence-Powered Medication Reconciliation Tool. Interact J Med Res 2016 May 16;5(2):e14 [FREE Full text] [doi: 10.2196/ijmr.5462] [Medline: 27185210]

95. Reddy M, Pesl P, Xenou M, Toumazou C, Johnston D, Georgiou P, et al. Clinical Safety and Feasibility of the Advanced Bolus Calculator for Type 1 Diabetes Based on Case-Based Reasoning: A 6-Week Nonrandomized Single-Arm Pilot Study. Diabetes Technol Ther 2016 Aug;18(8):487-493. [doi: 10.1089/dia.2015.0413] [Medline: 27196358]

96. Schiff GD, Volk LA, Volodarskaya M, Williams DH, Walsh L, Myers SG, et al. Screening for medication errors using an outlier detection system. J Am Med Inform Assoc 2017 Mar 01;24(2):281-287. [doi: 10.1093/jamia/ocw171] [Medline: 28104826]

97. Li Q, Spooner SA, Kaiser M, Lingren N, Robbins J, Lingren T, et al. An end-to-end hybrid algorithm for automated medication discrepancy detection. BMC Med Inform Decis Mak 2015 May 06;15:37 [FREE Full text] [doi: 10.1186/s12911-015-0160-8] [Medline: 25943550]

98. Carrell DS, Cronkite D, Palmer RE, Saunders K, Gross DE, Masters ET, et al. Using natural language processing to identify problem usage of prescription opioids. Int J Med Inform 2015 Dec;84(12):1057-1064. [doi: 10.1016/j.ijmedinf.2015.09.002] [Medline: 26456569]

99. Tinoco A, Evans RS, Staes CJ, Lloyd JF, Rothschild JM, Haug PJ. Comparison of computerized surveillance and manual chart review for adverse events. J Am Med Inform Assoc 2011;18(4):491-497 [FREE Full text] [doi: 10.1136/amiajnl-2011-000187] [Medline: 21672911]

100. Onay A, Onay M, Abul O. Classification of nervous system withdrawn and approved drugs with ToxPrint features via machine learning strategies. Comput Methods Programs Biomed 2017 Apr;142:9-19. [doi: 10.1016/j.cmpb.2017.02.004] [Medline: $\underline{28325450]}$

101. Cai R, Liu M, Hu Y, Melton BL, Matheny ME, Xu H, et al. Identification of adverse drug-drug interactions through causal association rule discovery from spontaneous adverse event reports. Artif Intell Med 2017 Feb;76:7-15 [FREE Full text] [doi: 10.1016/j.artmed.2017.01.004] [Medline: 28363289]

102. Dandala B, Joopudi V, Devarakonda M. Adverse Drug Events Detection in Clinical Notes by Jointly Modeling Entities and Relations Using Neural Networks. Drug Saf 2019 Jan;42(1):135-146. [doi: 10.1007/s40264-018-0764-x] [Medline: $\underline{30649738]}$

103. Dey S, Luo H, Fokoue A, Hu J, Zhang P. Predicting adverse drug reactions through interpretable deep learning framework. BMC Bioinformatics 2018 Dec 28;19(Suppl 21):476 [FREE Full text] [doi: 10.1186/s12859-018-2544-0] [Medline: 30591036]

104. Yang X, Bian J, Gong Y, Hogan WR, Wu Y. MADEx: A System for Detecting Medications, Adverse Drug Events, and Their Relations from Clinical Notes. Drug Saf 2019 Jan;42(1):123-133 [FREE Full text] [doi: 10.1007/s40264-018-0761-0] [Medline: $\underline{30600484]}$

105. Chapman AB, Peterson KS, Alba PR, DuVall SL, Patterson OV. Detecting Adverse Drug Events with Rapidly Trained Classification Models. Drug Saf 2019 Jan 16;42(1):147-156 [FREE Full text] [doi: 10.1007/s40264-018-0763-y] [Medline: 30649737]

106. Lian D, Khoshneshin M, Street WN, Liu M. Adverse drug effect detection. IEEE J Biomed Health Inform 2013 Mar;17(2):305-311. [doi: 10.1109/TITB.2012.2227272] [Medline: 24235108] 
107. Huang L, Wu X, Chen JY. Predicting adverse side effects of drugs. BMC Genomics 2011 Dec 23;12 Suppl 5:S11 [FREE Full text] [doi: 10.1186/1471-2164-12-S5-S11] [Medline: 22369493]

108. Wang Y, Coiera E, Runciman W, Magrabi F. Using multiclass classification to automate the identification of patient safety incident reports by type and severity. BMC Med Inform Decis Mak 2017 Jun 12;17(1):84 [FREE Full text] [doi: 10.1186/s12911-017-0483-8] [Medline: 28606174]

109. Ong M, Magrabi F, Coiera E. Automated identification of extreme-risk events in clinical incident reports. J Am Med Inform Assoc 2012 Jun;19(e1):e110-e118 [FREE Full text] [doi: 10.1136/amiajnl-2011-000562] [Medline: 22237865]

110. Dey S, Luo H, Fokoue A, Hu J, Zhang P. Predicting adverse drug reactions through interpretable deep learning framework. BMC Bioinformatics 2018 Dec 28;19(Suppl 21):476 [FREE Full text] [doi: 10.1186/s12859-018-2544-0] [Medline: 30591036]

111. Lehman CD, Wellman RD, Buist DSM, Kerlikowske K, Tosteson ANA, Miglioretti DL, Breast Cancer Surveillance Consortium. Diagnostic Accuracy of Digital Screening Mammography With and Without Computer-Aided Detection. JAMA Intern Med 2015 Nov;175(11):1828-1837 [FREE Full text] [doi: 10.1001/jamainternmed.2015.5231] [Medline: 26414882]

112. Hippisley-Cox J, Coupland C, Vinogradova Y, Robson J, Minhas R, Sheikh A, et al. Predicting cardiovascular risk in England and Wales: prospective derivation and validation of QRISK2. BMJ 2008 Jun 28;336(7659):1475-1482 [FREE Full text] [doi: $\underline{10.1136 / \mathrm{bmj} .39609 .449676 .25}$ ] [Medline: 18573856]

113. Iacobucci G. Computer error may have led to incorrect prescribing of statins to thousands of patients. BMJ $2016 \mathrm{May}$ 13;353:i2742. [doi: 10.1136/bmj.i2742] [Medline: 27178396 ]

114. NIST. Leadership in AI: A Plan for Federal Engagement in Developing Technical Standards and Related Tools. National Institute of Standards and Technology U.S. Department of Commerce. 2019 Sep 09. URL: https://www.nist.gov/system/ files/documents/2019/08/10/ai_standards_fedengagement_plan_9aug2019.pdf [accessed 2020-06-20]

115. Esteva A, Kuprel B, Novoa RA, Ko J, Swetter SM, Blau HM, et al. Dermatologist-level classification of skin cancer with deep neural networks. Nature 2017 Feb 02;542(7639):115-118. [doi: 10.1038/nature21056] [Medline: 28117445]

116. Winkler JK, Fink C, Toberer F, Enk A, Deinlein T, Hofmann-Wellenhof R, et al. Association Between Surgical Skin Markings in Dermoscopic Images and Diagnostic Performance of a Deep Learning Convolutional Neural Network for Melanoma Recognition. JAMA Dermatol 2019 Aug 14;155(10):1135. [doi: 10.1001/jamadermatol.2019.1735] [Medline: 31411641]

117. Executive Order 13859 - Maintaining American Leadership in Artificial Intelligence, 84 FR 3967. Federal Register: The Daily Journal of the Unites States Government. Washington DC: The White House; 2019 Feb 14. URL: https://www. federalregister.gov/documents/2019/02/14/2019-02544/maintaining-american-leadership-in-artificial-intelligence [accessed 2020-06-20]

118. Statement from FDA Commissioner Scott Gottlieb, M.D. on steps toward a new, tailored review framework for artificial intelligence-based medical devices. US Food and Drug Administration. 2019 Apr 02. URL: https://www.fda.gov/news-events/ press-announcements/statement-fda-commissioner-scott-gottlieb-md-steps-toward-new-tailored-review-framework-artificial [accessed 2020-06-20]

119. Kelly CJ, Karthikesalingam A, Suleyman M, Corrado G, King D. Key challenges for delivering clinical impact with artificial intelligence. BMC Med 2019 Oct 29;17(1):195 [FREE Full text] [doi: 10.1186/s12916-019-1426-2] [Medline: 31665002]

120. Collins GS, Reitsma JB, Altman DG, Moons KG. Transparent Reporting of a multivariable prediction model for Individual Prognosis Or Diagnosis (TRIPOD). Ann Intern Med 2015 May 19;162(10):735. [doi: 10.7326/115-5093-2]

121. Collins GS, Moons KGM. Reporting of artificial intelligence prediction models. Lancet 2019 Apr 20;393(10181):1577-1579. [doi: 10.1016/S0140-6736(19)30037-6] [Medline: $\underline{\text { 31007185] }}$

122. Huang J, Ling CX. Using AUC and accuracy in evaluating learning algorithms. IEEE Trans Knowl Data Eng 2005 Mar;17(3):299-310. [doi: 10.1109/TKDE.2005.50]

123. Stafford IS, Kellermann M, Mossotto E, Beattie RM, MacArthur BD, Ennis S. A systematic review of the applications of artificial intelligence and machine learning in autoimmune diseases. NPJ Digit Med 2020 Mar 9;3(1):30 [FREE Full text] [doi: 10.1038/s41746-020-0229-3] [Medline: $\underline{\text { 32195365] }}$

124. Paine SJ, Benator SG. JCAHO initiative seeks to improve patient safety. Medscape 2003;15(1):23-24.

125. Yang H, Poly TN, Jack Li YC. Deep into Patient care: An automated deep learning approach for reshaping patient care in clinical setting. Comput Methods Programs Biomed 2019 Jan;168:A1-A2. [doi: 10.1016/j.cmpb.2018.11.007] [Medline: 30527131]

126. Challen R, Denny J, Pitt M, Gompels L, Edwards T, Tsaneva-Atanasova K. Artificial intelligence, bias and clinical safety. BMJ Qual Saf 2019 Mar 12;28(3):231-237 [FREE Full text] [doi: 10.1136/bmjqs-2018-008370] [Medline: $\underline{30636200]}$

127. Bonafide CP, Localio AR, Holmes JH, Nadkarni VM, Stemler S, MacMurchy M, et al. Video Analysis of Factors Associated With Response Time to Physiologic Monitor Alarms in a Children's Hospital. JAMA Pediatr 2017 Jun 01;171(6):524-531 [FREE Full text] [doi: 10.1001/jamapediatrics.2016.5123] [Medline: 28394995]

128. Winters BD, Cvach MM, Bonafide CP, Hu X, Konkani A, O'Connor MF, Society for Critical Care Medicine AlarmAlert Fatigue Task Force. Technological Distractions (Part 2): A Summary of Approaches to Manage Clinical Alarms With Intent 
to Reduce Alarm Fatigue. Crit Care Med 2018 Jan;46(1):130-137. [doi: 10.1097/CCM.0000000000002803] [Medline: 29112077]

129. Hu X. An algorithm strategy for precise patient monitoring in a connected healthcare enterprise. NPJ Digit Med 2019;2:30 [FREE Full text] [doi: 10.1038/s41746-019-0107-z] [Medline: 31304377]

130. Woodward S. Moving towards a safety II approach. J Patient Safe Risk Manage 2019 Jun 08;24(3):96-99. [doi: $10.1177 / 2516043519855264$ ]

131. Woodward S. Implementing Patient Safety: Addressing Culture, Conditions, and Values to Help People Work Safely. New York: Routledge Productivity Press; 2019.

\author{
Abbreviations \\ AI: artificial intelligence \\ AUROC: area under the receiver operating characteristic curve \\ EHR: electronic health record \\ FDA: Food and Drug Administration \\ HHS: US Department of Health and Human Services \\ HIPAA: Health Insurance Portability and Accountability Act \\ MeSH: Medical Subject Headings \\ NIST: National Institute of Standards and Technology \\ PANDIT: Patient Assisting Net-Based Diabetes Insulin Titration \\ PRISMA: Preferred Reporting Items for Systematic Reviews and Meta-Analysis \\ TRIPOD: Transparent Reporting of a multivariable prediction model for Individual Prognosis Or Diagnosis
}

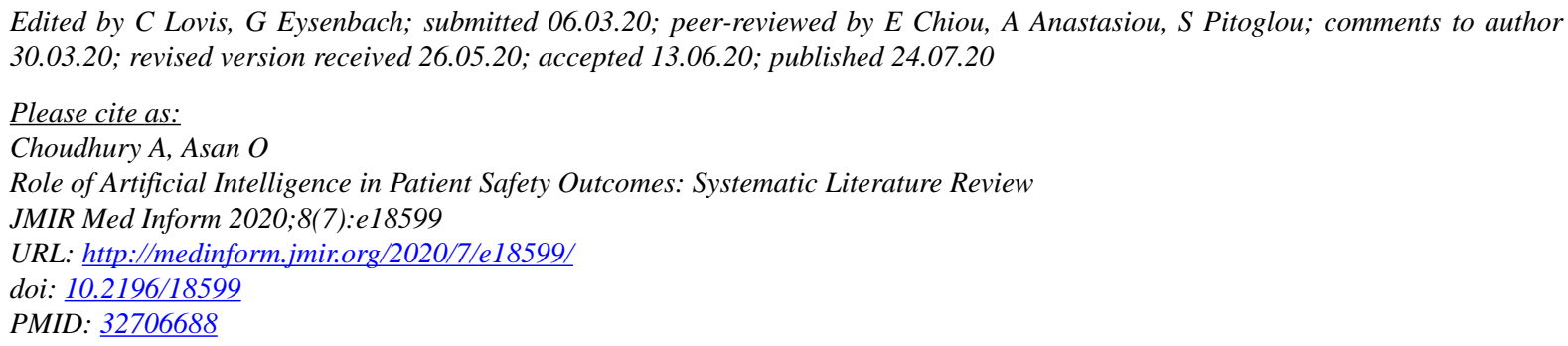

(C)Avishek Choudhury, Onur Asan. Originally published in JMIR Medical Informatics (http://medinform.jmir.org), 24.07.2020. This is an open-access article distributed under the terms of the Creative Commons Attribution License (https://creativecommons.org/licenses/by/4.0/), which permits unrestricted use, distribution, and reproduction in any medium, provided the original work, first published in JMIR Medical Informatics, is properly cited. The complete bibliographic information, a link to the original publication on http://medinform.jmir.org/, as well as this copyright and license information must be included. 